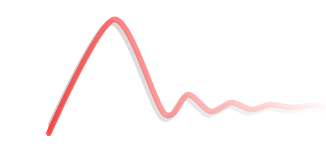

Dynare Working Papers Series https ://www.dynare.org/wp/

\title{
More Gray, More Volatile? Aging and (Optimal) Monetary Policy
}

\author{
Dániel Baksa \\ Zsuzsa Munkácsi
}

Working Paper no. 58

February 2020

\author{
C E P R E M A P \\ CENTRE POUR LA RECHERCHE ECONOMIQUE ET SES APPLCATIONS \\ 48, boulevard Jourdan - 75014 Paris - France \\ https: //www. cepremap.fr
}




\title{
More Gray, More Volatile? \\ Aging and (Optimal) Monetary Policy
}

\author{
Dániel Baksa ${ }^{\dagger}$ and Zsuzsa Munkácsi ${ }^{\nabla}$
}

October, 2019

\begin{abstract}
The empirical and theoretical evidence on the impact of population aging on inflation is mixed, and there is no evidence regarding the volatility of inflation. Using advanced economies' data and a DSGE-OLG model - a multi-period general equilibrium framework with overlapping generations - we find that aging leads to downward pressure on inflation and higher inflation volatility. Our paper shows how aging affects the short-term cyclical behavior of the economy and the transmission channels of monetary policy. We also examine the interplay between aging and optimal central bank policies. As aging redistributes wealth among generations, generations behave differently, and the labor force becomes more scarce. Our model suggests that aging makes monetary policy less effective, and aggregate demand less elastic to changes in the interest rate. Moreover, in grayer societies, central banks should react more strongly to nominal variables to compensate for higher inflation volatility.
\end{abstract}

Keywords: aging, monetary policy transmission, optimal monetary policy, inflation targeting

JEL codes: E31, E52, J11

The views expressed in this paper are those of the authors and do not necessarily represent the views of the IMF, its Executive Board, or IMF management. We thank Mihnea Constantinescu, Philipp Engler, Patrick Gruning, Zoltan Jakab, Julia Kiraly, Machiko Narita, Carolin Nerlich, Attila Ratfai, Balazs Romhanyi, Eszter Szabo-Bakos, Balazs Vilagi, one anonymous referee and the participants in the following events for their valuable comments: Bank of Lithuania (July and Aug 2017), Central European University (Jan 2018 and Sept 2018), the 2017 Conference of the Hungarian Society of Economists (Dec 2017), the 33rd Annual Congress of the EEA (Aug 2018), and the International Monetary Fund (Jan 2019). Any remaining errors are our own.

${ }^{\dagger}$ Department of Economics, Central European University; Institute for Capacity Development, International Monetary Fund; E-mail: Baksa_Daniel@phd.ceu.edu, DBaksa2@IMF.org

${ }^{\nabla}$ Strategy, Policy and Review Department, International Monetary Fund. Email: ZMunkacsi@ IMF.org 


\section{Contents}

Page

\begin{tabular}{ll}
\hline List of Tables & 4
\end{tabular}

\begin{tabular}{ll}
\hline List of Figures & 4
\end{tabular}

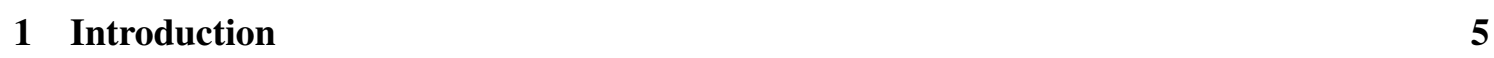

\begin{tabular}{lll}
\hline 2 & Literature review & 7
\end{tabular}

3 The Model 9

3.1 Demographics . . . . . . . . . . . . . . . . . . . . . . . 10

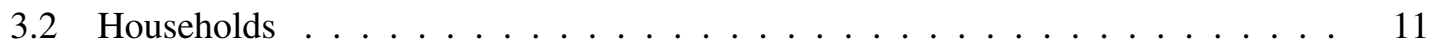

3.2 .1 Retired Households . . . . . . . . . . . . . . . . . . . . . . . . . 11

3.2 .2 Young Households $\ldots \ldots \ldots \ldots$. . . . . . . . . . . . . . . . . .

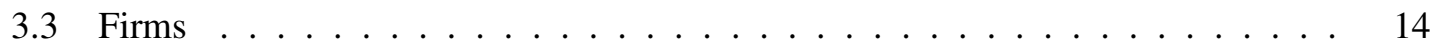

3.4 Fiscal Policy . . . . . . . . . . . . . . . . . . . . . . 17

3.5 Monetary Policy . . . . . . . . . . . . . . . . . . 18

3.6 Market Clearing Conditions $\ldots \ldots \ldots$. . . . . . . . . . . . . . . 19

\begin{tabular}{llr}
\hline 4 & Parametrization & 19
\end{tabular}

5 A Permanent Demographic Shift 22

6 Cyclical Behavior and Monetary Policy Transmission 24

$6.1 \quad$ Monetary Policy Shock . . . . . . . . . . . . . . . . . . . . . . 24

6.2 Government Expenditure Shock . . . . . . . . . . . . . . . . . . . 25

6.3 Supply Shock . . . . . . . . . . . . . . . . . . . . . . . . . . . . 27

6.4 Demographic structure and inflation volatility $\ldots \ldots \ldots \ldots$

$\begin{array}{lll}7 & \text { Welfare and Optimal Monetary Policy } & 30\end{array}$

7.1 The Model's State-Space Form . . . . . . . . . . . . . . . . . . . . 31

7.2 Welfare Loss Functions and Monetary Policy Rules . . . . . . . . . . . . . . . 32

7.3 Optimal Monetary Policy $\ldots \ldots \ldots$. . . . . . . . . . . . . . . . . 34

\begin{tabular}{lll}
\hline 8 & Conclusion & 37
\end{tabular} 


\section{List of Tables}

Page

$1 \quad$ Model parameters . . . . . . . . . . . . . . . . . . . . . . . 21

$2 \quad$ Steady-state comparison: young and gray societies f . . . . . . . . . . . 23

3 Descriptive statistics of observed variables: OECD countries between 1993 and

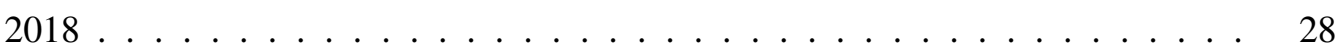

$4 \quad$ Volatility of inflation and old-dependency ratio $\ldots \ldots \ldots$

5 Calibrated standard deviation of variables and structural shocks . . . . . . . . . . 32

6 Old-age dependency ratios and welfare levels with the baseline monetary policy rules when using the ad hoc welfare loss function $\ldots \ldots \ldots 35$

$7 \quad$ Old-age dependency ratios and welfare levels with the baseline monetary policy rules when using the utility-based welfare loss function $\ldots \ldots$. . . . . . . 35

$8 \quad$ Old-age dependency ratios and age-dependent weights of the utility-based welfare

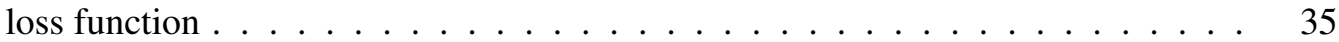

$9 \quad$ Old-age dependency ratios and optimal reaction parameters in six monetary policy regimes when using the ad hoc welfare loss function $\ldots . \ldots$. . . . . . . . . 36

$10 \quad$ Old-age dependency ratios and optimal reaction parameters in six monetary policy regimes by the utility-based welfare loss function $\ldots \ldots$. . . . . . . . . . 37

\section{List of Figures}

Page

1 Transition from a young society to an old one . . . . . . . . . . . . . 22

$2 \quad$ Impulse responses of a monetary policy shock $\ldots \ldots \ldots \ldots$

$3 \quad$ Impulse responses of a government expenditure shock . . . . . . . . . . . . . 26

$4 \quad$ Impulse responses of a supply shock $\ldots \ldots \ldots \ldots \ldots$

5 Core inflation and old-age dependency ratio . . . . . . . . . . . . . . . . . 29

\begin{tabular}{|lll}
\hline A1 Welfare functions with the baseline monetary policy rules by ad hoc welfare leos & 47
\end{tabular}

A2 Optimal reactions by ad hoc welfare loss (1) . . . . . . . . . . . . . 48

A3 $\quad$ Optimal reactions by ad hoc welfare $\operatorname{loss}(2) \ldots \ldots \ldots$. . . . . . . . . . . . . 49

A4 Welfare functions with the baseline monetary policy rules by utility function . . . 50

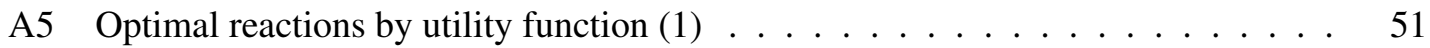

A6 $\quad$ Optimal reactions by utility function $(2) \ldots \ldots \ldots \ldots$. . . . . . . . . 52 
"Old age is like a plane flying through a storm. Once you're aboard there's nothing you can do."

Golda Meir (1898-1978)

"But there is something central banks can do."

The authors

\section{Introduction}

In 2012, ${ }^{1}$, William C. Dudley, then president of the Federal Reserve Bank of New York, remarked (Dudley 2012) that "the weaker than expected recovery [since the recent crisis] likely lies in the interplay between secular and cyclical factors", and "demographic factors have played a role in [it]." Thus, in addition to stressing the more straightforward fiscal consequences of aging, Dudley drew attention to the interaction between demographics, nominal variables, and central bank policies. Specifically, he noted that the spending decisions of older-age cohorts are less likely to be easily stimulated by monetary policy, as such age groups tend to spend less of their income on consumer durables and housing.

Dudley's comment signaled a longstanding interest of central bankers in population aging. $\mathrm{Nu}$ merous empirical and theoretical papers discuss the longer-term monetary (inflation rate, but not inflation volatility) and interest-rate implications of aging. According to the secular stagnation literature, slower economic growth is coupled with a fall in the natural rate of interest (examples include Summers (2014), Favero and Galasso (2015), Eggertsson, Mehrotra, and Robbins (2017), Ferrero, Gross, and Neri (2017) and Jones (2018)). ${ }^{2}$ Many studies have treated the shorter-term behavior of the macroeconomy and monetary policy transmission (but not based on a multi-period general equilibrium framework with overlapping generations), which we will discuss next. To be best of our knowledge, though, the interplay between aging and optimal monetary policies has been completely overlooked in the literature.

Wong (2018) and Miyamoto and Yoshino (2017) are the closest to our framework, and arrive at similar conclusions. Nevertheless, Wong (2018) presents a partial equilibrium life-cycle model, that is, a household model of mortgages and housing. ${ }^{3}$ Hence, she does not take all the general equilibrium channels and effects into account. For their part, Miyamoto and Yoshino(2017) do not

\footnotetext{
1 https://www.newyorkfed.org/newsevents/speeches/2012/dud121015

${ }^{2}$ There is also a related stream on the zero lower bound; however, this topic is beyond the scope of the present paper. Additionally, regarding the cyclical volatility of real variables, Jaimovich and Siu (2009) report that the workforce age composition has a large and significant effect on the cyclical volatility of hours worked.

${ }^{3}$ It is beyond the scope of this paper to review the literature on the role of household balance sheets (e.g., debt and housing) in detail.
} 
incorporate overlapping generations into their framework: the retirees simply are rule-of-thumb agents who consume all of their transfers (pensions). To the best of our knowledge, our model is the first multi-period dynamic general equilibrium model with overlapping generations to explore the short-term cyclical behavior of the macroeconomy and the monetary policy transmission mechanism in the presence of aging.

The model is a dynamic general equilibrium model with demographics and overlapping generations, following Baksa and Munkacsi (2016). Population changes over time, and there are two cohorts: the young (workers) and the old (retired). We assume a simple production sector (one sector with a Cobb-Douglas utility function), a simple labor market block (only labor supply, no unemployment), a simple fiscal block (only lump-sum taxes), and consider a closed economy ${ }^{4}$. The model is parametrized for an advanced economy, and the standard deviations are calibrated to the moments of the euro area time series.

Aging is a challenge: it changes the relative and absolute sizes of each cohort. An increase in longevity increases the number and share of the elderly. If the fertility rate (birth rate) also declines, in addition to the higher old-age dependency ratio, the number of the young declines as well. The most important channel is that as agents live longer and their planning horizon becomes longer, their savings position changes: the young are willing to borrow relatively more and finance the increasing pay-as-you-go pension system, while the retired accumulate more savings to guarantee their consumption over a longer time horizon. The young and the old also make different consumption-savings decisions. In particular, there are age-dependent elasticities of intertemporal substitution in the model, as the old are less sensitive to changes in monetary conditions than the young. ${ }^{5}$ Hence, when the interest rate changes, it has different implications for the young and the old: higher interest rates imply an extra cost for the young, who are indebted, while the old generate higher income. Finally, aging has labor market implications: when the labor force shrinks, the labor market becomes tighter, that is, the labor supply is more inelastic (the Frisch-elasticity decreases as the old-age dependency ratio increases). This also affects real wages: the more scarce the labor supply, the more profound the real wage reaction to shocks. ${ }^{6}$ Our model suggests that

\footnotetext{
${ }^{4}$ As stressed by Batini, Callen, and McKibbin (2006), Boersch-Supan, Ludwig, and Winter (2006), and Krueger and Ludwig (2007), open-economy channels matter in multi-country or global settings. In particular, closed-economy predictions for a decline in the interest rate tend to be overstated, that is, capital mobility tends to moderate the pressure on factor price adjustments.

5 Wong (2018) provides empirical estimates of age-specific consumption elasticities to interest rate shocks. The consumption of younger people is twice as responsive to interest rate shocks than that of older people, and explains about two-third of the aggregate response. The consumption responses are driven by homeowners who refinance or enter new loans after the interest rate declines. This implies that under an older demographic structure, aggregate consumption will respond less to monetary policy shocks.

${ }^{6}$ Additionally, according to the literature, there are other channels as well: the old consume fewer durable goods and housing, and spend more on health than the young; and the old also tend to shift their portfolio towards safer assets
} 
aging contributes positively to inflation volatility, while monetary policy becomes less effective and the aggregate demand less elastic to changes in the interest rate. To compensate for higher inflation volatility, the central bank should react more strongly to nominal variables.

The rest of the paper is structured as follows: in Section 2, we summarize the relevant literature on this topic, while in Section 3 we describe the equations of the model, which is a simplified version of Baksa and Munkacsi (2016). In Section 4, we discuss how to parametrize the framework. Section 5 demonstrates the steady states of young and old societies. Then, in Section 6, we present the main impulse-response functions and, in particular, explore the transmission mechanism of monetary policy and show empirical evidence for higher inflation volatility in aging societies. Next, Section 7 is devoted to studying the welfare consequences of aging and optimal monetary policy rules. Finally, in Section 8, we summarize the main policy conclusions.

\section{Literature review}

The related literature consists of several empirical and theoretical papers. In addition to the cited papers in the introduction, we provide further references on relevant overlapping generation models. At the same time, we review the empirical findings.

A number of empirical papers investigate the impact of population aging and demographics on the rate of inflation. The findings are contradictory. Many report that aging puts a downward pressure on inflation. For example, Kim, Lee, and Yoon (2014), based on a panel dataset covering 30 OECD economies between 1960 and 2013, find that population growth affects the inflation rate positively. Lindh and Malmberg (1998) and Lindh and Malmberg (2000) estimate the relation between inflation and aging also on OECD data between 1960-1994 for 20 countries, and claim that increases in the population of net savers dampen inflation, while net consumers have a positive effect on it (young retirees fan inflation as they start consuming out of accumulated pension claims). At the same time, Juselius and Takats (2015) and Juselius and Takats (2016) introduce the age-structure-inflation puzzle, that is, they report that aging increases inflation. Specifically, based on a panel of 22 advanced economies over the period 1955-2010, they show that both young and old dependents are inflationary, whereas the working-age population is disinflationary. In our paper, which is based on data from several advanced economies, we will present evidence that aging is associated with lower inflation. Moreover, in a panel regression of OECD countries, we provide evidence on the positive impact of aging on inflation volatility.

(e.g., government bonds). These channels are not directly modeled in our framework. 
Several authors have explored the effect of aging on monetary policy transmission. Imam (2013) and Imam (2014) report that, in graying societies, more aggressive monetary policy is needed because such policy becomes less effective with aging. The author, based on Bayesian estimation techniques for the U.S., Canada, Japan, the U.K., and Germany, confirms the weakening of monetary policy effectiveness over time, and provides evidence - using dynamic panel-OLS techniques - that this is attributable to demographic changes. Relatedly, Deok Ryong and Dong-Eun (2017) perform a panel-VAR analysis using OECD data between 1995 and 2014, reporting that monetary policies lose their effectiveness considerably as aging hits the economy.

Additionally, structural models are considered, on the one hand, when examining the long-run inflationary, interest rate, and savings rate impacts of aging and, on the other, when exploring the transition path between the steady states of less and grayer economies, or the impulse responses of monetary policy shocks in an aged society. The findings are somewhat mixed, although most authors claim that aging has a significant impact on nominal variables and monetary policy transmission - that is, it increases inflation and reduces the effectiveness of monetary policy transmission. Nonetheless, we are not aware of any multi-period general equilibrium model with overlapping generations in this literature; the available models are two-period or partial equilibrium models, or they lack important overlapping generation or pension aspects. Furthermore, to the best of our knowledge, the interplay between aging and optimal monetary policies has not yet been explored in the literature at all.

Fujiwara and Teranishi (2017), based on a closed-economy overlapping generations framework a la Gertler (1999), find that longevity lowers the natural interest rate, but aging does not significantly alter the impulse responses of monetary policy shocks. Nevertheless, as pointed out by Ripatti (2008), in the absence of aging-related fiscal policy and social security aspects, the study does not explore the links between demographics, pensions, and monetary policy. Hence, the results arise from the fact that the retirees' population share is not large enough, even in an aged society. Similarly, Kara and von Thadden (2010) report that demographic changes, while contributing slowly over time to a decline in the equilibrium interest rate, are not visible enough within the time horizon relevant for policy-making to require monetary policy reactions. They develop a small-scale DSGE model, calibrated for the euro area, which embeds a demographic structure within a monetary policy framework by extending Gertler (1999) such that the short-run dynamics are similar to the paradigm summarized in Woodford (2003). Nonetheless, they do not treat monetary policy transmission in their paper.

At the same time, Carvalho and Ferrero (2014), based on a calibrated model of a dynamic monetary 
economy with a life-cycle structure a la Gertler $(1999)$ for Japan, point out that an increase in life expectancy puts a downward pressure on the effective real interest rate. Kantur (2013), in a twoperiod OLG New Keynesian model, and Carvalho, Ferrero, and Nechio (2016), in a life-cycle model calibrated for developed economies, also come to the conclusion that the natural rate of interest decreases as the old-age dependency ratio increases. Kantur (2013) also claims that the effectiveness of monetary policy decreases due to a decrease in interest rate sensitivity of the society as the population ages. Similarly, Auerbach, Kotlikoff, Hagemann, and Nicoletti (1989) and Auerbach, Cai, and Kotlikoff (1991), using three different types of models, among others a life-cycle model, and Rios-Rull (2001) - based on Spanish data - report that aging negatively influences the long-term savings rate. Anderson, Botman, and Hunt (2014), based on the IMF's Global Integrated Monetary and Fiscal (GIMF) model, find that aging causes deflation, mainly via slowing growth and falling land prices. Baesel and McMillan (1990) claim that as the Baby Boomers age, it is reasonable to expect that the unemployment rate and the real interest rates will become lower. Further, Miles (1999), in a general equilibrium model with overlapping generations for the UK and Europe, show that there will be a radical decline in saving rates as a result of an increase in the old-age dependency ratio. Other examples in this stream of the literature include Miles (2002), Katagiri and Ueda (2014), and Faruqee and Muhleisen(2003).

\section{The Model}

Demographics and overlapping generations are modeled following Baksa and Munkacsi (2016). We distinguish two cohorts, that is, the $20+$ generation is divided into working and retired agents. In each period the number of working-age population changes by an exogenous net fertility rate. In addition, there is a given probability of retirement, with no age-specific retirement probabilities within the cohort. The number of the retired increases because some of the young retire, while we also assume a cohort-specific probability of death (Gertler 1999$)$.

Workers decide how much to consume and save, and supply labor; they receive labor income and dividends from the firms. Only the young cohort pays taxes to the government, which is used to finance the pension system and other public expenditures. Retired agents receive pension benefits from the pay-as-you-go (PAYG) pension system: upon each agent's retirement, the government calculates a level of pension benefits that is assumed to be fixed in real terms (or, to put it differently, in nominal terms the government adjusts it with the inflation rate every year). Retired households decide how much of their previous income they wish to spend on consumption, or 
save. Since state-contingent bonds are assumed, young agents are able to fully insure themselves against any possible survival outcomes.

The production block follows standard neoclassical assumptions and Calvo-style price rigidity. The firms are responsible for physical capital accumulation and investment activity, and they demand labor. In this model, we do not assume productivity growth on the balanced-growth path.

The paper examines the role of monetary policy and short-run cyclical behavior. In the baseline scenario, we consider a standard Taylor-type reaction function, and at a later stage we test the model's robustness using various policy rules. The rest of this section describes the main technical assumptions and the parametrization of the framework.

\subsection{Demographics}

First of all, we need to define the demographic structure of the economy. Total population $\left(N_{t}\right)$ is equal to the sum of the old (the retired) $\left(N_{t}^{O}\right)$ and the young (workers) $\left(N_{t}^{Y}\right)$ :

$$
N_{t}=N_{t}^{O}+N_{t}^{Y}
$$

Agents become retired with $\omega^{Y}$ probability and $n$ is the net fertility rate, i.e. the share of the new-coming workers:

$$
N_{t}^{Y}=\left(1-\omega_{t-1}^{Y}\right) N_{t-1}^{Y}+n_{t} N_{t-1}^{Y}
$$

Only $1-\omega^{O}$ of the retired survive and live in the next period:

$$
N_{t}^{O}=\left(1-\omega_{t-1}^{O}\right) N_{t-1}^{O}+\omega_{t-1}^{Y} N_{t-1}^{Y}
$$

Similarly to other standard general equilibrium models with population growth, we focus on the relative shares of different cohorts, and not on their levels. $s_{t}$ denotes the ratio of the number of old and young people (i.e., the old-age dependency ratio), while $s_{t}^{Y}$ is the share of young people in the whole population. Based on the above assumptions, we can express the ratios as a function of 
the survival probabilities and the fertility rate:

$$
\begin{aligned}
& s_{t}=\frac{N_{t}^{O}}{N_{t}^{Y}}=\frac{\left(1-\omega_{t-1}^{O}\right)}{\left(1-\omega_{t-1}^{Y}+n_{t}\right)} s_{t-1}+\frac{\omega_{t-1}^{Y}}{\left(1-\omega_{t-1}^{Y}+n_{t}\right)} \\
& s_{t}^{Y}=\frac{N_{t}^{Y}}{N_{t}}=\frac{1}{1+s_{t}}
\end{aligned}
$$

The young, the old, and total population growth can then be expressed as functions of the relative ratios and survival probabilities:

$$
\begin{aligned}
1+g_{t}^{N, Y} & =\frac{N_{t}^{Y}}{N_{t-1}^{Y}}=1-\omega_{t-1}^{Y}+n_{t} \\
1+g_{t}^{N, O} & =\frac{N_{t}^{O}}{N_{t-1}^{O}}=\left(1-\omega_{t-1}^{O}\right)+\frac{\omega_{t-1}^{Y}}{s_{t-1}} \\
1+g_{t}^{N} & =\frac{N_{t}}{N_{t-1}}=\left(1+g_{t}^{N, Y}\right) \frac{1+s_{t}}{1+s_{t-1}}
\end{aligned}
$$

\subsection{Households}

Households optimize their lifetime utility; nevertheless, several individuals, that is, overlapping generations, live. In the next sections, we present the individuals' decisions and their consumption functions, and calculate the cohort-level aggregate variables as well. The solution for the households' problem is based on backward induction, which means that we start with the retired individuals' optimization, and, conditional on the expected behavior of retired agents, we can also solve the young households' optimization problem.

\subsubsection{Retired Households}

'Retired' agent $i$ of retired cohort $a$ is one individual who retired $a$ years ago. Each agent maximizes the following Bellman equation:

$$
V^{O}\left(B_{a-1, t-1}^{O}(i)\right)=\max \left\{\frac{1}{1-\gamma}\left\{C_{a, t}^{O}(i)\right\}^{1-\gamma}+\beta E_{t}\left(1-\omega_{t}^{O}\right) V^{O}\left(B_{a, t}^{O}(i)\right)\right\}
$$

subject to this budget constraint:

$$
C_{a, t}^{O}(i)+\left(1-\omega_{t}^{O}\right) B_{a, t}^{O}(i)=\left(1+r_{t-1}\right) B_{a-1, t-1}^{O}(i)+T R_{a, t}^{Y O}(i)
$$


where $C^{O}(i)$ denotes the individual consumption of the retired agent, $B^{O}(i)$ is individual savings, $\gamma$ is the inverse of the intertemporal elasticity of substitution, $\beta$ is the discount factor, $r$ is the real interest rate, and $T R^{Y O}(i)$ is the level of retirement benefits which was calculated at the time of retirement.

The first-order conditions imply the Euler equation that describes the substitution between the current and future individual retired consumption levels:

$$
\beta E_{t} \frac{\left(C_{a+1, t+1}^{O}(i)\right)^{-\gamma}}{\left(C_{a, t}^{O}(i)\right)^{-\gamma}}\left(1+r_{t}\right)=1
$$

After some simplifications and introducing some additional variables, the final version of the consumption of agent $i$ of cohort $a$ at time $t$ is as follows:

$$
\begin{aligned}
& C_{a, t}^{O}(i)=M P C_{t}^{O} T R_{a, t}^{Y O}(i) \Omega_{t}^{O}+M P C_{t}^{O}\left(1+r_{t-1}\right) B_{a-1, t-1}^{O}(i) \\
& \Omega_{t}^{O}=1+E_{t} \frac{1-\omega_{t}^{O}}{1+r_{t}} \Omega_{t+1}^{O} \\
& \frac{1}{M P C_{t}^{O}}=1+E_{t}\left(1-\omega_{t}^{O}\right)\left(1+r_{t}\right)^{\frac{1}{\gamma}-1} \beta^{\frac{1}{\gamma}} \frac{1}{M P C_{t+1}^{O}}
\end{aligned}
$$

Here, $T R_{n, t+n}^{Y O}(i)=T R_{0, t}^{Y O}(i)$ for all $n>0$. Following the conventions, we introduce the marginal propensity to consume of the retired cohort as $M P C^{O}$. The cohort-level consumption $\left(C^{O}\right)$ and savings $\left(B^{O}\right)$ are as follows (for the technical details, see Baksa and Munkacsi (2016)):

$$
C_{t}^{O}=M P C_{t}^{O} T R_{t} \Omega_{t}^{O}+\left(1+r_{t-1}\right) M P C_{t}^{O}\left(\omega_{t-1}^{Y} B_{t-1}^{Y}+B_{t-1}^{O}\right)
$$

where the $T R_{t} \Omega_{t}^{O}$ is the present value of the expected retirement benefits. The retired cohort's consumption depends on the present value of expected revenues and accumulated wealth from the previous periods, and the marginal propensity to consume shows the proportion of lifetime income spent on consumption, which is a function of the real interest rate and the survival probability.

\subsubsection{Young Households}

'Young' agent $i$ of cohort $b$ is one individual of its cohort who started to work (was born) $b$ years ago. The dynamic optimization problem of the young can be described by the following Bellman 
equation:

$$
\begin{aligned}
V_{t}^{Y}\left(B_{b-1, t-1}^{Y}(i)\right)= & \max \left\{\frac{1}{1-\gamma}\left\{C_{b, t}^{Y}(i)^{\sigma}\left(1-L_{b, t}(i)\right)^{1-\sigma}\right\}^{1-\gamma}\right. \\
& \left.+E_{t}\left(\left(1-\omega_{t}^{Y}\right) \beta V_{t+1}^{Y}\left(B_{b, t}^{Y}(i)\right)+\omega_{t}^{Y} \beta V_{t+1}^{O}\left(B_{b, t}^{Y O}(i)\right)\right)\right\}
\end{aligned}
$$

while the budget constraint is:

$C_{b, t}^{Y}(i)+\left(1-\omega_{t}^{Y}\right) B_{b, t}^{Y}(i)+\omega_{t}^{Y} B_{b, t}^{Y O}(i)=\left(1+r_{t-1}\right) B_{b-1, t-1}^{Y}(i)+w_{t} L_{b, t}(i)+\operatorname{Profit}_{b, t}(i)-\operatorname{Tax}_{b, t}(i)$

Here, $C^{Y}(i)$ denotes the young individual's consumption, $L(i)$ is her labor supply, $\sigma$ is the weight of consumption in the one-period utility function, $\operatorname{Tax}(i)$ is the lump-sum tax, Profit $(i)$ denotes the dividend from firms, and $w$ is the real wage. A young agent saves for two possible future states; we assume state contingent bonds, for saving young, the workers save into $B^{Y}(i)$; and for the next period retired-self, the worker today saves into $B^{Y O}(i)$. We assume full insurance; this means that any outcome will happen in a future period, and the workers' previous period savings are transferred into their own young-self or retired-self account.

Due to the presence of state-contingent bonds, the optimization problem of young households results in two Euler equations, that is, young households are able to insure themselves against the future retired status as well:

$$
\begin{aligned}
& \beta E_{t} \frac{\left(C_{b+1, t+1}^{Y}(i)^{\sigma}\left(1-L_{b+1, t+1}(i)\right)^{1-\sigma}\right)^{-\gamma} C_{b+1, t+1}^{Y}(i)^{\sigma-1}\left(1-L_{b+1, t+1}(i)\right)^{1-\sigma}}{\left(C_{b, t}^{Y}(i)^{\sigma}\left(1-L_{b, t}(i)\right)^{1-\sigma}\right)^{-\gamma} C_{b, t}^{Y}(i)^{\sigma-1}\left(1-L_{b, t}(i)\right)^{1-\sigma}}\left(1+r_{t}\right)=1 \\
& \beta E_{t} \frac{\left(C_{b+1, t+1}^{O}(i)\right)^{-\gamma}}{\left(C_{b, t}^{Y}(i)^{\sigma}\left(1-L_{b, t}(i)\right)^{1-\sigma}\right)^{-\gamma} \sigma C_{b, t}^{Y}(i)^{\sigma-1}\left(1-L_{b, t}(i)\right)^{1-\sigma}}\left(1+r_{t}\right)=1
\end{aligned}
$$

In addition, the young decide about their labor supply:

$$
\frac{C_{b, t}^{Y}(i)}{1-L_{b, t}(i)}=\frac{\sigma}{1-\sigma} w_{t}
$$

After some simplifications and by introducing additional variables, we can write up the young 
individual's consumption function as follows:

$$
\begin{aligned}
C_{b, t}^{Y}(i) & =M P C_{t}^{Y} \operatorname{Inc}_{b, t}^{Y}(i)+\operatorname{MPC}_{t}^{Y}\left(1+r_{t-1}\right) B_{b-1, t-1}^{Y}(i) \\
\operatorname{Inc}_{b, t}^{Y}(i) & =w_{t}+\operatorname{Profit}_{b, t}(i)-\operatorname{Tax}_{b, t}(i)+ \\
& +E_{t} \frac{\omega_{t}^{Y}}{1+r_{t}} \operatorname{TR}_{0, t+1}^{Y O}(i) \Omega_{t+1}+E_{t} \frac{1-\omega_{t}^{Y}}{1+r_{t}} \operatorname{Inc}_{b, t}^{Y}(i) \\
\frac{1}{M P C_{t}^{Y}} & =\frac{1}{\sigma}+E_{t}\left(1+r_{t}\right)^{\frac{1}{\gamma}-1}\left[\left(1-\omega_{t}^{Y}\right) \Lambda_{t}^{Y} \frac{1}{M P C_{t+1}^{Y}}+\omega_{t}^{Y} \Lambda_{t}^{Y O} \frac{1}{M P C_{t+1}^{O}}\right] \\
\Lambda_{t}^{Y} & =E_{t} \beta^{\frac{1}{\gamma}}\left(\frac{w_{t+1}}{w_{t}}\right)^{(1-\sigma)\left(1-\frac{1}{\gamma}\right)} \\
\Lambda_{t}^{Y O} & =E_{t}\left\{\frac{\beta}{\sigma}\right\}^{\frac{1}{\gamma}}\left(\frac{1}{\frac{\sigma}{1-\sigma} w_{t}}\right)^{(1-\sigma)\left(1-\frac{1}{\gamma}\right)}
\end{aligned}
$$

Here, $M P C^{Y}$ is the marginal propensity of the young to consume, and $\operatorname{Inc} c^{Y}(i)$ is the discounted sum of the current and present value of expected incomes and future pension benefits.

Based on the individual consumption function, we can express the aggregate consumption function and the aggregate income function as follows:

$$
\begin{aligned}
C_{t}^{Y} & =M P C_{t}^{Y} \operatorname{Inc}_{t}^{Y}+\left(1+r_{t-1}\right) M P C_{t}^{Y}\left(1-\omega_{t-1}^{Y}\right) B_{t-1}^{Y} \\
\operatorname{Inc}_{t}^{Y} & =w_{t} N_{t}^{Y}+\text { Profit } t_{t}-\operatorname{Tax}_{t}+E_{t} \frac{1}{1+r_{t}} T R_{t+1}^{Y O} \Omega_{t+1}^{O}+E_{t} \frac{1-\omega_{t}^{Y}}{\left(1+r_{t}\right)\left(1+g_{t+1}^{N, Y}\right)} \operatorname{Inc}_{t+1}^{Y}
\end{aligned}
$$

Since there are two distinct cohorts, and both can accumulate risk-free bonds, one of the budget constraints closes the model; the aggregate young budget constraint is as follows:

$$
C_{t}^{Y}+B_{t}^{Y}=w_{t} L_{t}+\text { Profit }_{t}-\text { Tax }_{t}+\left(1+r_{t-1}\right)\left(1-\omega_{t-1}^{Y}\right) B_{t-1}^{Y}
$$

\subsection{Firms}

We assume monopolistic competition and price stickiness a la Calvo: in every period, a fraction of $1-\omega^{P}$ of firms has a chance to change the nominal price level; the rest of them can only adjust the previously agreed prices by the previous period's aggregate inflation rate (Calvo 1983; , Milani 2005). The optimization problem is conditional on the expectation of the Calvo lottery. As a result, all firms maximize the present value of current and expected future profit flows subject to the production function, the demand function, and the capital accumulation equation. In other 
words, the firm $j$ maximizes

$$
E_{t} \sum_{n=0}^{\infty} \omega^{P^{n}} \prod_{k=1}^{n} \frac{1-\omega_{t+k-1}^{Y}}{1+i_{t+k-1}}\left(P_{t}^{*}(j)\left(\frac{P_{t+n-1}}{P_{t-1}}\right)^{\gamma_{P}} Y_{t+n}(j)-V_{t+n} L_{t+n}(j)-P_{t+n} \operatorname{In} v_{t+n}(j)\right)
$$

subject to:

$$
\begin{aligned}
Y_{t}(j) & =e^{-\varepsilon_{t}^{P}} A_{t} K_{t-1}(j)^{\alpha} L_{t}(j)^{1-\alpha} \\
Y_{t}(j) & =\left(\frac{P_{t}^{*}(j)}{P_{t}}\right)^{-\varphi_{P}} Y_{t} \\
K_{t}(j) & =\operatorname{Inv}_{t}(j)\left(1-S\left(\frac{\operatorname{In} v_{t}(j)}{\operatorname{Inv} v_{t-1}(j)}\right)+(1-\delta) K_{t-1}(j)\right. \\
S\left(\frac{\operatorname{Inv}_{t}(j)}{\left(1+g_{t}^{N}\right) \operatorname{Inv}_{t-1}(j)}\right) & =\frac{\phi_{\text {Inv }}\left(1+\xi_{t}^{\operatorname{Inv}}\right)}{2}\left(\frac{\operatorname{In} v_{t}(j)}{\left(1+g_{t}^{N}\right) \operatorname{Inv}_{t-1}(j)}-1\right)^{2}
\end{aligned}
$$

Here, $i$ denotes the nominal interest rate, and the young households are the owners of the firms; thus, their survival probability is also taken into account. $P^{*}(j)$ denotes the individual optimal nominal prices, which are adjusted by the inflation rate. Further, $\operatorname{Inv}(j)$ is the real investment variable, which is multiplied by the aggregate price index; $\alpha$ is the capital share in the CobbDouglas production function; $\delta$ is the depreciation rate of capital; $\varphi_{P}$ is the price elasticity for $Y(j)$ demanded individual products; $\gamma_{P}$ is the degree of price indexation; and $S(\cdot)$ is the convex investment adjustment cost function, with $\phi_{I n v}$ cost parameter and $\xi^{I n v}$ investment shock. $\varepsilon_{t}^{P}$ denotes the supply shock, which is only defined in a sticky price equilibrium. We also assume nominal wage stickiness a la Calvo, and $V$ denotes the relevant nominal wage index.

Taking the first-order conditions, we can derive the usual input demand functions and marginal cost functions:

$$
\begin{aligned}
\alpha \frac{Y_{t}(j)}{K_{t-1}(j)} m c_{t} & =r_{t}^{K} \\
(1-\alpha) \frac{Y_{t}(j)}{L_{t}(j)} m c_{t} & =v_{t} \\
m c_{t} & =e^{\varepsilon_{t}^{P}} \frac{1}{A_{t}}\left(\frac{r_{t}^{K}}{\alpha}\right)^{\alpha}\left(\frac{v_{t}}{1-\alpha}\right)^{1-\alpha}
\end{aligned}
$$

where $r^{K}$ denotes the marginal product of capital, for simplification we use this variable in the rest of the paper.

Because the firms are responsible for physical capital accumulation, the set of first-order condi- 
tions also contain the Tobin-Q equation and a no-arbitrage condition:

$$
\begin{aligned}
& Q_{t}\left(1-S\left(\frac{\operatorname{Inv}_{t}(j)}{\left(1+g_{t}^{N}\right) \operatorname{In} v_{t-1}(j)}\right)-S^{\prime}\left(\frac{\operatorname{Inv}_{t}(j)}{\left(1+g_{t}^{N}\right) \operatorname{In} v_{t-1}(j)}\right) \frac{\operatorname{Inv}_{t}(j)}{\operatorname{In} v_{t-1}(j)}\right)= \\
& =1-E_{t} \frac{1-\omega_{t}^{Y}}{1+r_{t}} Q_{t+1} S^{\prime}\left(\frac{\operatorname{Inv}_{t+1}(j)}{\left(1+g_{t+1}^{N}\right) \operatorname{Inv}_{t}(j)}\right)\left(\frac{\operatorname{Inv}_{t+1}(j)}{\operatorname{In} v_{t}(j)}\right)^{2} \\
& E_{t}\left(1-\omega_{t}^{Y}\right)\left(r_{t+1}^{K}+Q_{t+1}(1-\delta)\right)=Q_{t}\left(1+r_{t}\right)
\end{aligned}
$$

Next, the monopolistic firm sets the optimal price $\left(p^{*}\right)$ as follows:

$$
\begin{aligned}
p_{t}^{*} & =\frac{\varphi_{P}}{\varphi_{P}-1} \frac{\mathscr{Z}_{t}^{1}}{\mathscr{Z}_{t}^{2}} \\
\mathscr{Z}_{t}^{1} & =p_{t}^{*-\varphi_{P}} Y_{t} m c_{t}+E_{t}\left(\frac{p_{t}^{*}}{p_{t+1}^{*}} \frac{\left(1+\pi_{t}\right)^{\gamma_{P}}}{1+\pi_{t+1}}\right)^{-\varphi_{P}} \omega_{P}\left(1-\omega_{t}^{Y}\right) \frac{1+\pi_{t+1}}{1+i_{t}} \mathscr{Z}_{t+1}^{1} \\
\mathscr{Z}_{t}^{2} & =p_{t}^{*-\varphi_{P}} Y_{t}+E_{t}\left(\frac{p_{t}^{*}}{p_{t+1}^{*}} \frac{\left(1+\pi_{t}\right)^{\gamma_{P}}}{1+\pi_{t+1}}\right)^{-\varphi_{P}} \frac{\left(1+\pi_{t}\right)^{\gamma_{P}}}{1+i_{t}} \omega_{P}\left(1-\omega_{t}^{Y}\right) \mathscr{Z}_{t+1}^{2}
\end{aligned}
$$

Based on the definition of the price index, we can express the optimal individual relative price as a function of actual and previous inflation rates:

$$
1=\left(1-\omega_{P}\right) p_{t}^{* 1-\varphi_{P}}+\omega_{P}\left(\frac{\left(1+\pi_{t-1}\right)^{\gamma_{P}}}{1+\pi_{t}}\right)^{1-\varphi_{P}}
$$

The effective labor cost for the firms differs from the workers' real wage. We assume that workers supply their labor force to a labor unions and that these unions, with their monopolistic power, set the profit-maximizing effective nominal wage. However, not all unions are able to set their optimal wage in each periods. Next, the optimization problem of the labor unions can be given as follows:

$$
E_{t} \sum_{n=0}^{\infty} \omega_{V}^{n} \prod_{k=1}^{n} \frac{1-\omega_{t+k-1}^{Y}}{1+i_{t+k-1}}\left(V_{t}^{*}(j)\left(\frac{V_{t+n-1}}{V_{t-1}}\right)^{\gamma_{V}} L_{t+n}(j)-W_{t+n} L_{t+n}(j)\right)
$$

subject to

$$
L_{t}(j)=\left(\frac{V_{t}^{*}(j)}{V_{t}}\right)^{-\varphi_{W}} L_{t}
$$

where $\omega_{V}$ is the fraction of unions that are not able to set their prices in a given period. $V^{*}(j)$ denotes the individual optimal nominal wage adjusted by the wage inflation rate. $\varphi_{W}$ is the wage elasticity for labor, and $\gamma_{V}$ is the degree of price indexation. The monopolistic labor union sets the 
optimal nominal wage as follows:

$$
\begin{aligned}
v_{t}^{*} & =\frac{\varphi_{V}}{\varphi_{V}-1} \frac{\mathscr{W}_{t}^{1}}{\mathscr{W}_{t}^{2}} \\
\mathscr{W}_{t}^{1} & =\left(\frac{v_{t}^{*}}{v_{t}}\right)^{-\varphi_{W}} L_{t} w_{t}+E_{t}\left(\frac{v_{t}^{*}}{v_{t+1}^{*}} \frac{\left(1+\pi_{t}^{V}\right)^{\gamma_{V}}}{1+\pi_{t+1}^{V}}\right)^{-\varphi_{V}} \frac{\omega_{V}\left(1-\omega_{t}^{Y}\right)\left(1+\pi_{t+1}\right)}{1+i_{t}} \mathscr{W}_{t+1}^{1} \\
\mathscr{W}_{t}^{2} & =\left(\frac{v_{t}^{*}}{v_{t}}\right)^{-\varphi_{V}} L_{t}+E_{t}\left(\frac{v_{t}^{*}}{v_{t+1}^{*}} \frac{\left(1+\pi_{t}^{V}\right)^{W}}{1+\pi_{t+1}^{V}}\right)^{-\varphi_{V}} \frac{\omega_{V}\left(1-\omega_{t}^{Y}\right)\left(1+\pi_{t}^{V}\right)^{\gamma_{V}}}{1+i_{t}} \mathscr{W}_{t+1}^{2}
\end{aligned}
$$

Similarly, based on the definition of the price index, we can express the optimal individual relative wage as a function of actual and previous wage inflation and real aggregate wage indices:

$$
1=\left(1-\omega_{V}\right)\left(\frac{v_{t}^{*}}{v_{t}}\right)^{1-\varphi_{V}}+\omega_{V}\left(\frac{\left(1+\pi_{t-1}^{V}\right)^{\gamma_{V}}}{1+\pi_{t}^{V}}\right)^{1-\varphi_{V}}
$$

where the $\pi^{V}$ is the nominal wage inflation, which can be given as:

$$
1+\pi_{t}^{V}=\left(1+\pi_{t}\right) \frac{v_{t}}{v_{t-1}}
$$

Here, $v$ denotes the union wage in real terms. Last, the profits of firms and the labor union go to the young:

$$
\text { Profit }=Y_{t}-w_{t} L_{t}-\operatorname{Inv}_{t}
$$

\subsection{Fiscal Policy}

The role of fiscal policy is limited in this paper. The government is responsible for providing payas-you-go pension benefits, and it finances its expenditures by taxing the young cohort or issuing public debt:

$$
\operatorname{Debt}_{t}+\operatorname{Tax}_{t}=T R_{t}+\text { Gov }_{t}+\left(1+r_{t-1}\right) \operatorname{Debt}_{t-1}
$$

where the Debt is the level of public debt, and we chose a Tax lump-sum tax rule that sustains the initial $\frac{D e b t}{Y}$ ratio:

$$
\operatorname{Tax}_{t}=T R_{t}+\text { Gov }_{t}+\left(1+r_{t-1}\right) \operatorname{Debt}_{t-1}-\left\{\frac{\text { Debt }}{Y}\right\}^{\text {Target }} Y_{t}
$$


In the PAYG-regime individual $(i)$ 's pension benefits in the year of retirement $t$ are based on the replacement rate $v$ and the pre-retirement labor income:

$$
T R_{0, t}^{Y O}(i)=v w_{t-1} L_{b-1, t-1}(i)
$$

The aggregated version of the pension rules is:

$$
T R_{t}^{Y O}=v \omega_{t-1}^{Y} w_{t-1} L_{t-1}
$$

Furthermore, the total pension expenditure of all retired agents can be described as a function of pension benefits and survival probabilities:

$$
T R_{t}=\sum_{n=0}^{\infty} \prod_{k=1}^{n}\left(1-\omega_{t-k}^{O}\right) T R_{t-n}^{Y O}
$$

which can be simply rewritten in recursive form as:

$$
T R_{t}=T R_{t}^{Y O}+\left(1-\omega_{t-1}^{O}\right) T R_{t-1}
$$

\subsection{Monetary Policy}

Initially, the central bank follows a simple rule with inflation reaction and interest rate smoothing:

$$
1+i_{t}=\left(1+i_{t-1}\right)^{\rho_{i}}\left(\left(1+r_{t}^{n}\right)\left(1+\pi_{t}\right)^{\phi_{\pi}}\right)^{1-\rho_{i}} e^{\varepsilon_{t}^{i}}
$$

where $\varepsilon_{t}^{i}$ is the monetary policy shock. By assumption, the central bank raises the interest rate if inflation exceeds its steady-state level. Since prices are sticky, the central bank is able to influence the real economy's performance via the interest rate channel. $r^{n}$ is the natural interest rate that is consistent with the flexible-price version of the model. The Fisher-identity expresses the relationship between the nominal and real interest rates:

$$
1+i_{t}=E_{t}\left(1+r_{t}\right)\left(1+\pi_{t+1}\right)
$$




\subsection{Market Clearing Conditions}

Finally, we need to clarify the market clearing conditions. Since there is no government debt, the sum of the two cohorts' savings should be equal with public debt.

$$
\operatorname{Debt}_{t}=B_{t}^{Y}+B_{t}^{O}
$$

In the goods market, all supplied goods are equal to the demanded consumption goods, investment, and government expenditure:

$$
Y_{t}=C_{t}^{Y}+C_{t}^{O}+\operatorname{Inv}_{t}+\text { Gov }_{t}
$$

\section{Parametrization}

In this paper, we are concerned with general patterns. Thus, we parametrize the model by choosing typical parameter values in the DSGE literature. Table 1 shows the chosen parameter values. Specifically, we use the Pessoa model, that is, the Portuguese version of the GIMF model (Almeida, Castro, Maria, Julio, and Felix (2013)), and the New Area-Wide Model (Christoffel, Coenen, and Warne (2008)).

Based on the Pessoa model, we calibrated the households' time preference $(\beta)$, risk aversion $(\gamma)$ and weight of consumption $(\sigma)$ in the utility function. The price and wage elasticities $(\varphi$ and $\left.\varphi_{W}\right)$, capital share $(\alpha)$, depreciation rate $(\delta)$, Calvo parameters $\left(\omega_{P}\right.$ and $\left.\omega_{W}\right)$ and indexation parameters $\left(\gamma_{P}\right.$ and $\left.\gamma_{W}\right)$, investment adjustment cost $\left(\phi_{I n v}\right)$, inflationary reaction $\left(\phi_{\pi}\right)$ and interest smoothing $\left(\rho_{i}\right)$ of the monetary policy rule are taken from the New Area-Wide Model. Regarding the calibration of the demographic parameters, we consider data on Germany, Portugal, Spain and Slovakia published by the Eurostat. Particularly, we choose the fertility rate, probability of retirement and mortality rate such that we match on the average probabilities and the old-age dependency ratio in the 80s. The replacement rate and the size of the pension system are based on Istenič, Hammer, Šeme, Lotrič Dolinar, and Sambt (2016), who measure the overall income redistribution from the worker to the retired cohort. The government consumption-to-GDP ratio is calibrated to the government individual consumption of European countries, while the steady-state public debt-to-GDP ratio is the Maastricht criterium, that is, 60 percent.

As we express all variables in per capita values and solve the steady state of the normalized model, we need a candidate for the steady-state value of the equilibrium real interest rate. Conditional 
on this assumed level of the real interest rate, we can calculate all the other endogenous variables. As a final step, we check whether the financial market equilibrium condition holds; if it does not, another starting value for the steady-state real interest rate is chosen, and the process starts again. ${ }^{7}$

In this paper, we deal with short-run cyclical fluctuations, where the sizes of the discount rates, the interest rate, and labor supply elasticities play a crucial role. They reflect the relative importance of different channels for different instruments used in the model. First, the interest rate elasticity from the non-separable utility function (i.e. the intertemporal substitution) can be derived as follows:

$$
\varepsilon=-\frac{U_{C(i)}}{U_{C(i), C(i)} C(i)}=\frac{1}{1+\sigma(\gamma-1)}
$$

Retired agents do not supply labor $(\sigma=1)$, which means that the $\varepsilon$-s are cohort-specific. The parametrized values are based on typical values in the DSGE literature, and the dynamic responses are relatively close to those estimated by Wong (2018) for the old and the young, respectively.

Next, the Frisch labor supply elasticity can only be calculated for the young cohort:

$$
\eta=\frac{U_{L(i)}}{L(i)\left(U_{L(i), L(i)}-\frac{U_{C(i), L(i)}^{2}}{U_{C(i), C(i)}}\right)}=\frac{s^{Y}-\tilde{L}}{\tilde{L}} \frac{1-\sigma(1-\gamma)}{\gamma}
$$

where $\tilde{L}$ is the normalized level of labor. Our specification is consistent with the available microeconomic estimates (such as that of Whalen and Reichling (2017)). Namely, the Frisch elasticity is a function of the steady-state demographic and labor market variables. Thus, aging directly changes the relative size of cohorts and the supply of labor: the labor force shrinks and the labor market becomes tighter with aging. Relatedly, labor supply becomes less elastic (the Frisch-elasticity decreases as the old-age dependency ratio increases), and the volatility of real wages is intensified (the scarcer the labor supply, the more profound the real wage reaction to shocks) (Table 3).

\footnotetext{
${ }^{7}$ The same approach was followed in Baksa and Munkacsi (2016)
} 


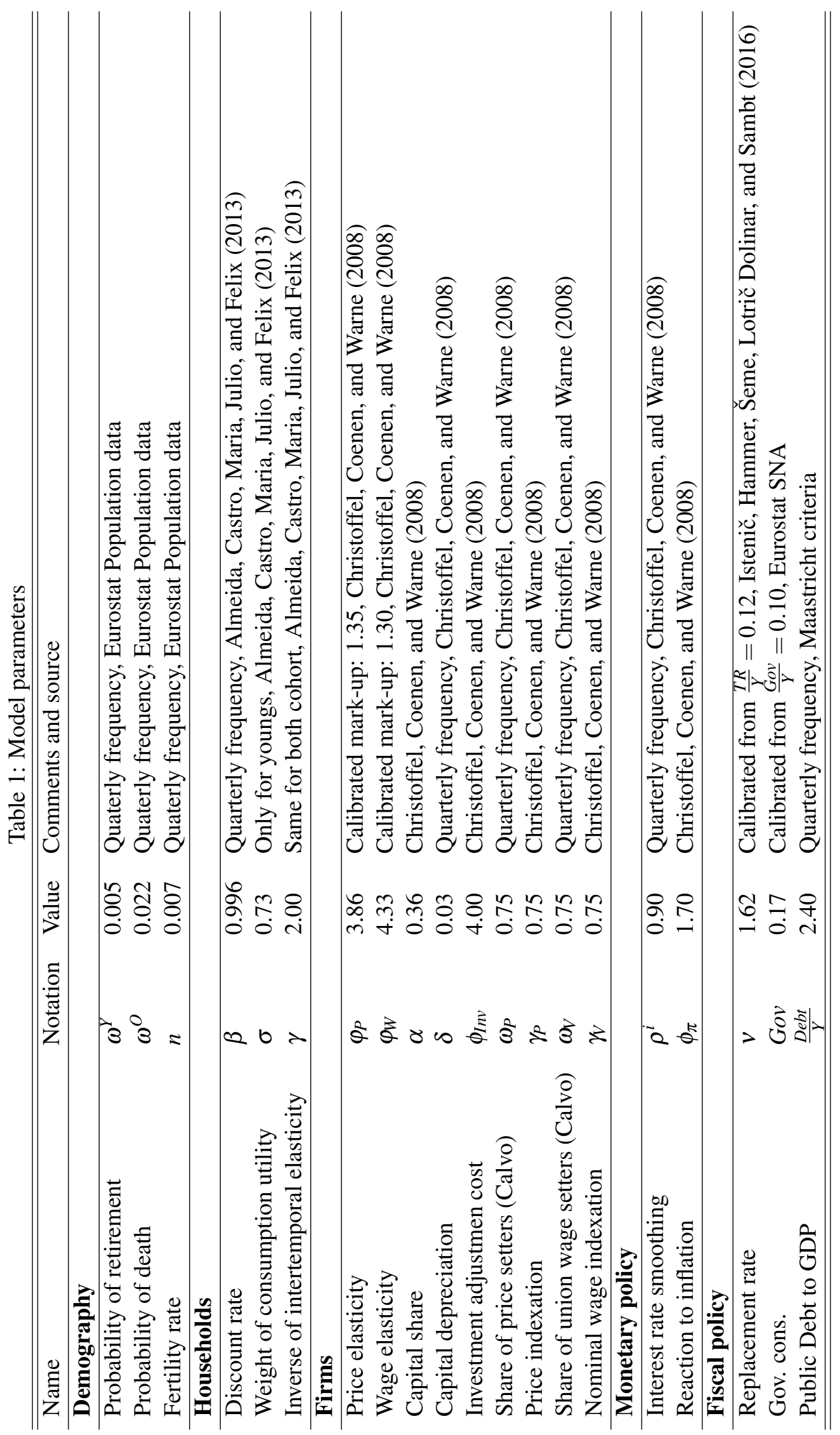




\section{A Permanent Demographic Shift}

In this paper, we mainly consider (i) how aging affects the short-run cyclical behavior of the macroeconomy, and (ii) how optimal monetary policies change with aging. Before doing so in Sections 6 and 7, though, in this section we demonstrate a transition from a young society to an old one. Specifically, Table 2 shows the steady-state comparison of a young and an old society when the fertility rate decreases from $3 \%$ to $1.7 \%$, the probability of death decreases from $9 \%$ to $3.65 \%$ in 20 years, and the old-age dependency ratio gradually increases from 20 to 60 percent, while Figure $1^{8}$ the transition path between the two steady states under the PAYG system, the results are consistent with Baksa (2019).

Figure 1: Transition from a young society to an old one
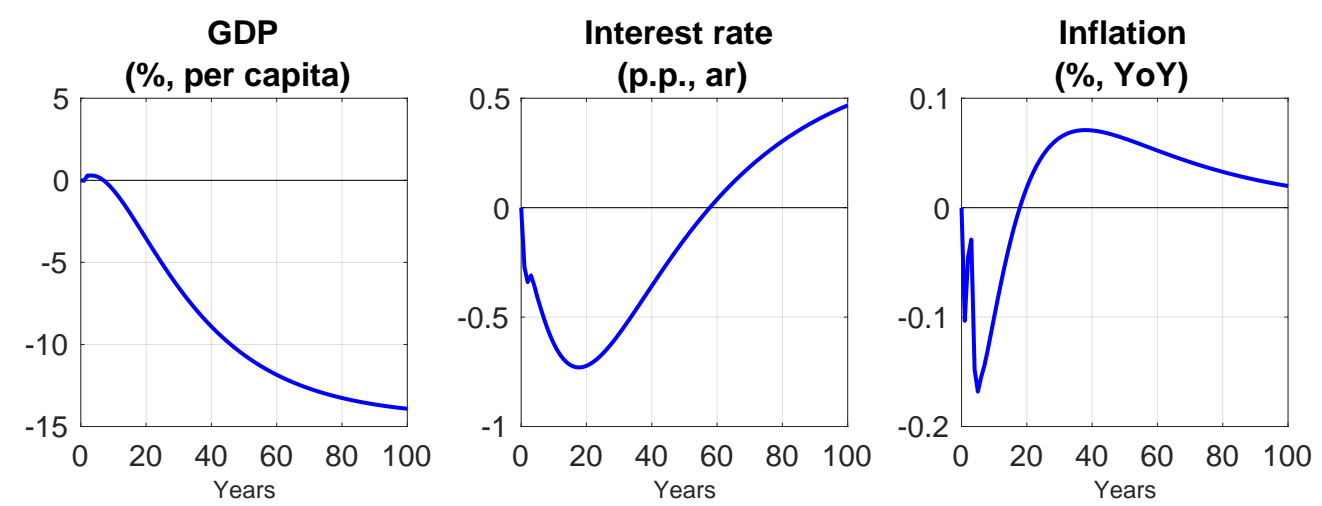

Old-age dependency ratio
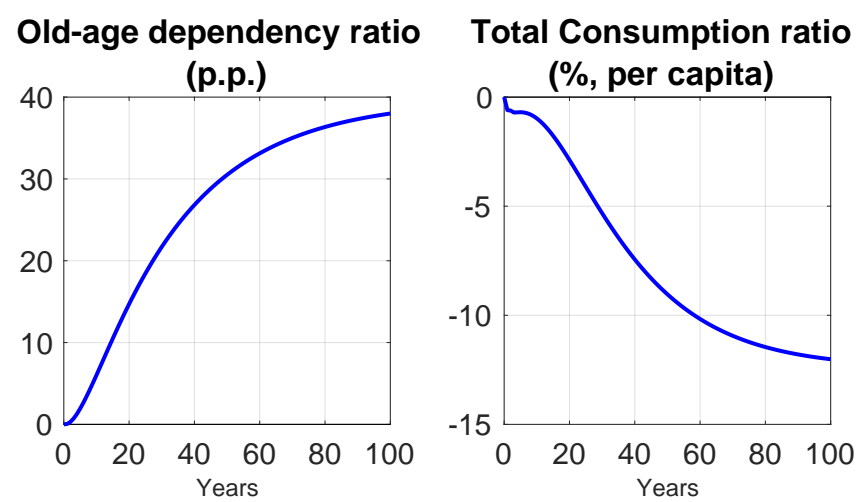

Investment

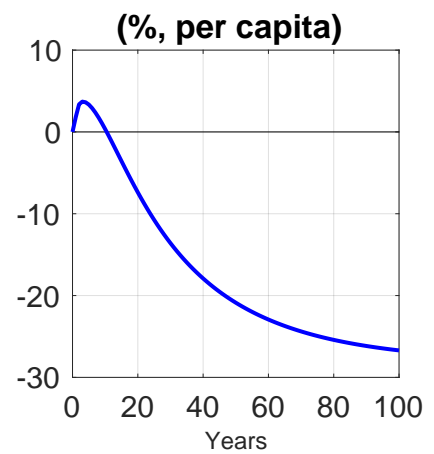

8 "ar" is an abbreviation for annualized rate. 
Due to the longer lifetime horizon (decreasing $\omega^{O}$ ), retired households accumulate more savings. At the same time, the PAYG pension system is required to provide a higher amount of pension benefits, which can be financed by taxes deducted from the young workers. So, young agents face an increasing financing need from the pension system, and, due to consumption smoothing (and to minimize their own sacrifice), their indebtedness increases. The higher private indebtedness and the higher financing needs of the government with an extended pension system elevates the long-term real interest rate Baksa(2019).

Table 2: Steady-state comparison: young and gray societies

\begin{tabular}{llll}
\hline \hline Name & Notation & $\begin{array}{c}\text { Young } \\
\text { society }\end{array}$ & $\begin{array}{l}\text { Graying } \\
\text { society }\end{array}$ \\
\hline Demography & & & \\
\hline Old-age dependency ratio & $s$ & 0.20 & 0.60 \\
Share of the young & $s^{Y}$ & 0.83 & 0.63 \\
\hline Households & & & \\
\hline Consumption to GDP: Total & $\frac{C}{Y}$ & 0.69 & 0.71 \\
Consumption to GDP: Young & $\frac{C^{Y}}{Y}$ & 0.56 & 0.33 \\
Consumption to GDP: Old & $\frac{C^{O}}{Y}$ & 0.13 & 0.37 \\
Bonds to GDP: Old & $\frac{B^{O}}{Y}$ & 0.44 & 3.14 \\
Bonds to GDP: Young & $\frac{B^{Y}}{Y}$ & 1.96 & -0.74 \\
Interest rate elasticity: Young & $\varepsilon^{Y}$ & 0.58 & 0.58 \\
Interest rate elasticity: Old & $\varepsilon^{O}$ & 0.50 & 0.50 \\
Frisch elasticity & $\eta$ & 0.49 & 0.29 \\
\hline Firms & \multicolumn{3}{l}{} \\
\hline GDP & $Y$ & 1.67 & 1.43 \\
Investment to GDP & $\frac{I n v}{Y}$ & 0.21 & 0.18 \\
Capital to GDP & $\frac{K}{Y}$ & 7.71 & 7.32 \\
Profit to GDP & $\frac{P r f i t}{Y}$ & 0.42 & 0.46 \\
\hline Monetary policy & & & \\
\hline Real interest rate & $r$ & 0.00 & 0.01 \\
\hline Fiscal policy & & & \\
\hline Transfer to GDP & $\frac{T R}{Y}$ & 0.12 & 0.35 \\
Public consumption to GDP & $\frac{G o v}{Y}$ & 0.10 & 0.12 \\
\hline \hline & & & \\
\hline
\end{tabular}

Regarding the supply side of the economy, via lower fertility and a shrinking labor force, the firms accommodate to the new situation: they realize the decrease in demand, so they gradually disinvest and reduce prices (generate disinflation or deflation) to offset the loss in profits. However, in the medium term, instead of investing in physical capital, they hire relatively more labor. The decreasing free labor capacities increase the real wage, and in the tighter labor market the real wage becomes more volatile and more responsive to short-run shocks as the Frisch elasticity decreases. Due to the labor shortages, real wages rise, and inflation goes back to its steady-state level. The central bank first decreases the interest rate to compensate for the downward pressure on inflation. However, in the long run, it gradually normalizes the policy rate, since inflation goes back to its 
steady-state level. The lower level of physical capital stock and the increased marginal product of capital are consistent with the higher equilibrium interest rate in the new steady state.

\section{Cyclical Behavior and Monetary Policy Transmission}

We now turn to presenting the dynamic properties of the model. In a young and an old society, we compare the short-run cyclical reactions of the macroeconomy to a monetary policy shock, a government expenditure shock, and a supply shock. We examine one-off, temporary shocks only, that is, all the impulse response functions converge back to the demographic-specific steady state. ${ }^{9}$

\subsection{Monetary Policy Shock}

It is well known that if the central bank deviates from its systematic Taylor-rule, that is, if it increases the nominal interest rate, then, because of price stickiness, it also changes the real interest rate - and so can influence the performance of the real economy (Figure 2). Tighter monetary policy conditions force firms to postpone investment, and households to start accumulating more savings or decreasing their credit stock. Due to the shrinking aggregate demand, share $1-\omega^{P}$ of the firms decrease their prices to avoid (reduce) the loss in profits. Due to price stickiness and price indexation, the nominal adjustment is gradual, and disinflation takes more than 4 quarters. The central bank observes the shrinking aggregate demand and decreases the nominal interest rate back to its steady-state level, and the whole economy stabilizes at its initial steady state.

Aging generates differences in the output gap reaction (the deviation of GDP from its flexible-price equilibrium level). This is also reflected in the fact that the young and the old respond differently. Specifically, in an old society, the retired agents hold more savings, while the workers have more debt during their longer lifetime. Additionally, in a young society, the monetary restriction creates an incentive for postponing consumption and increasing savings. However, in an old society, the interest rate hike has an even more asymmetric effect: the old can interpret the shock as additional income; thus, later, they increase consumption by a larger amount, while the young face higher credit costs and decrease consumption more. Because aging also changes the relative size of cohorts, aggregate consumption and output gap fall less in gray societies. Hence, we find that aging reallocates the asset position among generations, which makes monetary policy

\footnotetext{
${ }^{9}$ In all simulations, we assume that in young societies (on Figures 2-4 labeled without Aging) the old-age dependency ratio is $20 \%$, and in old societies (on Figures 2-4 labeled Aging) $60 \%$. On the same figures is an abbreviation for the annualized rate.
} 
less effective - defined as a larger drop in the inflation rate to the same monetary tightening and aggregate demand less elastic to interest rate changes. Our finding is consistent with that of Wong (2018) who, based on micro-level cohort-specific US data, shows that the old react less to expansionary monetary policy shocks.

Figure 2: Impulse responses of a monetary policy shock
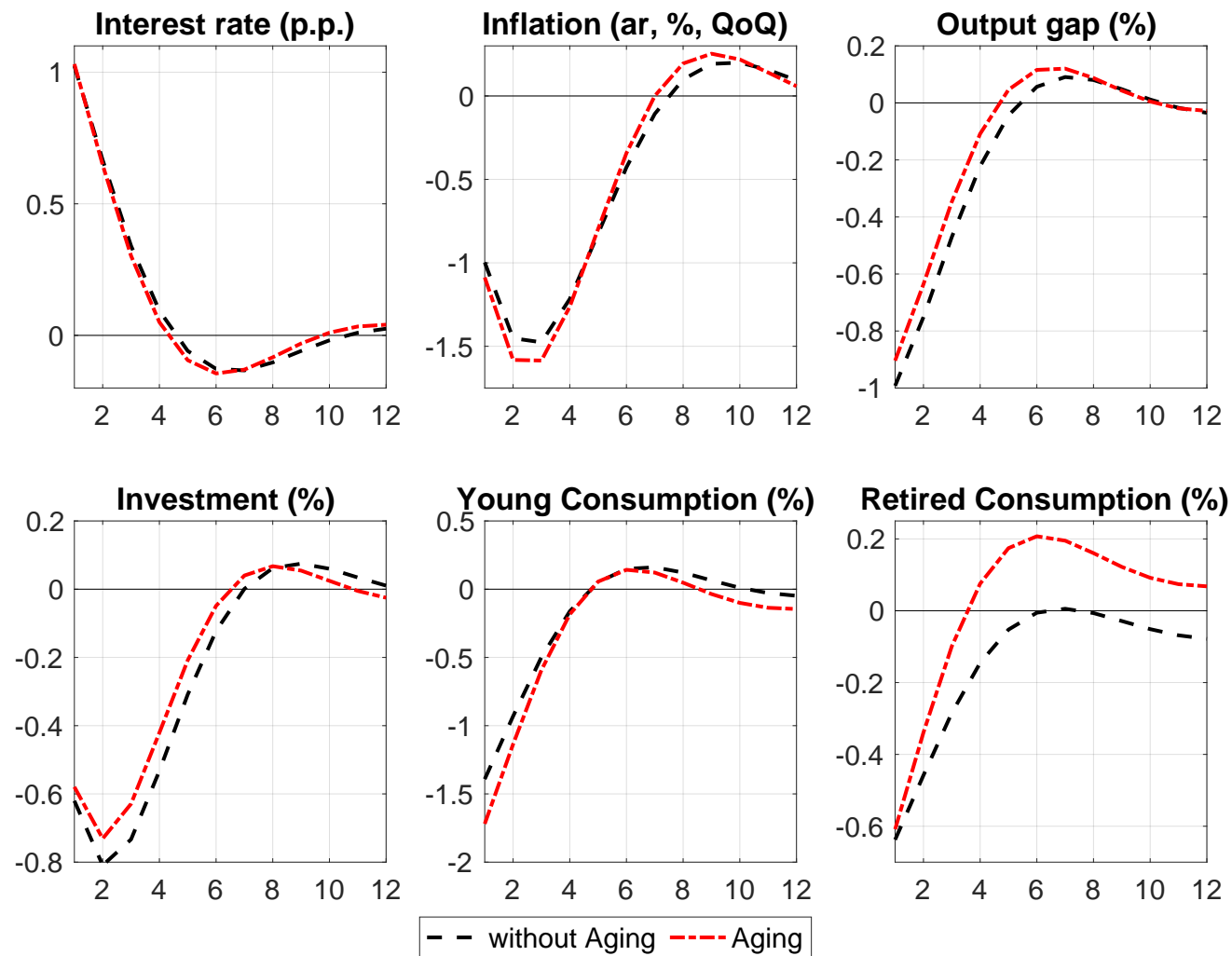

\subsection{Government Expenditure Shock}

The government increases public expenditure by one percent of the steady-state GDP (Figure 3). As a result, firms increase production to satisfy the extra demand. A higher level of production requires more labor, so firms increase wages to attract more workers. To offset the increase in production costs and the loss in profits, price-setting firms increase their prices. The central bank launches a tightening cycle, and holds the interest rate elevated until the demand-side inflationary pressure disappears and inflation goes back to its original steady-state level. Due to the increase in 
wages, young households consume more. Old households consume less because of the increasing interest rate and credit demand (from the young households). Later on, though, the higher interest rates push young consumption down and old consumption up.

Aging also changes the relative size of cohorts, and decreases the available labor force in the economy. In an old society, the labor supply is more inelastic (the Frisch-elasticity is lower). Hence, firms are forced to increase wages more than in a young society. This additional increase in wages amplifies the increase in marginal costs and inflation, too. As a consequence, in an old society, the central bank needs to raise the policy rate by a larger amount than it does in a young society. A stronger monetary policy reaction in a grayer society forces the young to give up more consumption.

Figure 3: Impulse responses of a government expenditure shock
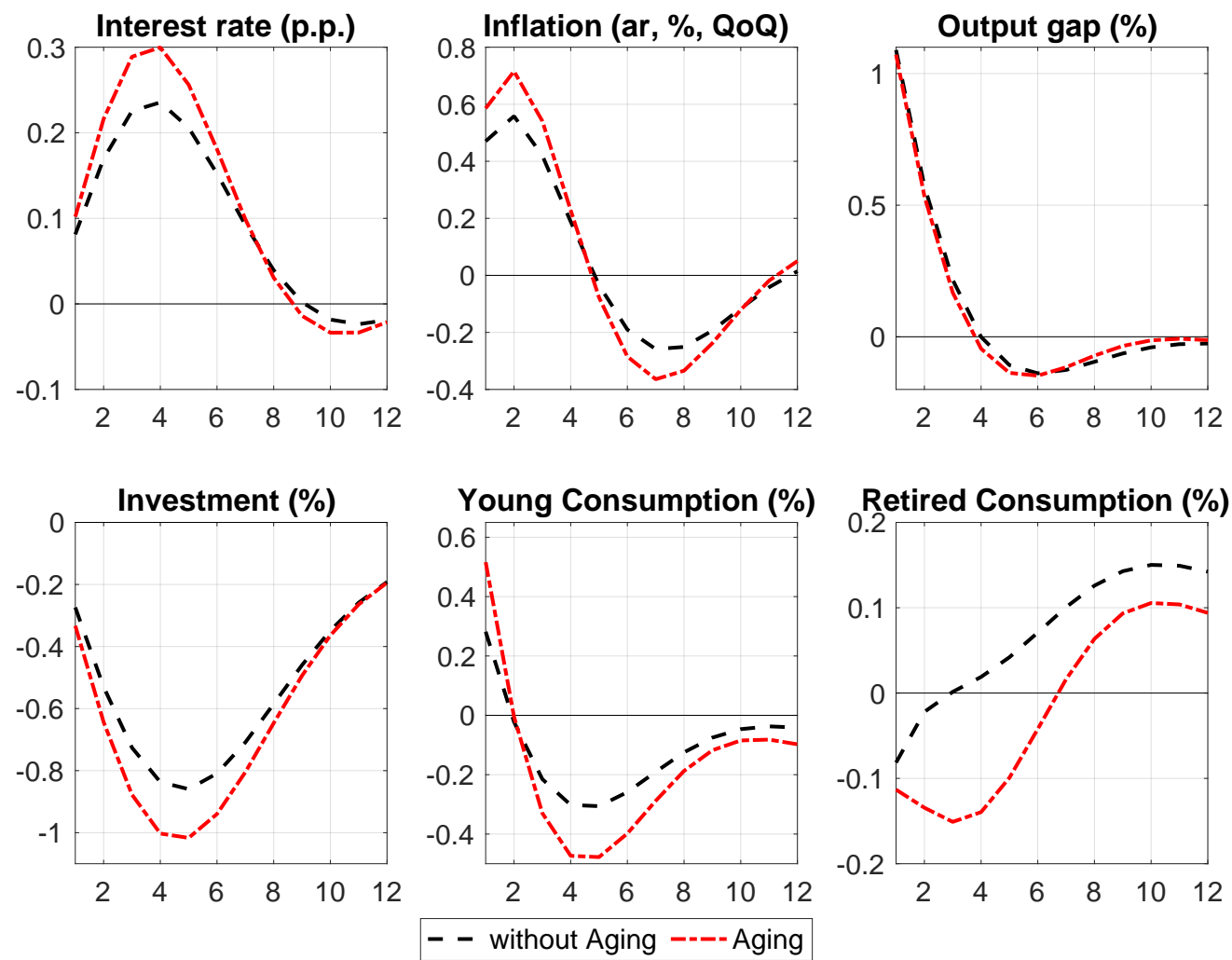


\subsection{Supply Shock}

The main channel of the supply shock is that price-setting firms decide to increase prices to improve profitability, or offset profit losses (Figure 4). Due to higher inflation, the central bank increases the nominal interest rate, which forces households and firms to postpone expenditure items (consumption and investment, respectively). Observing the fall in domestic demand, firms decide to give up on further price increases; consequently, inflation starts to normalize. As a result, the central bank reduces the policy rate, and the economy stabilizes around its original steady state.

Figure 4: Impulse responses of a supply shock
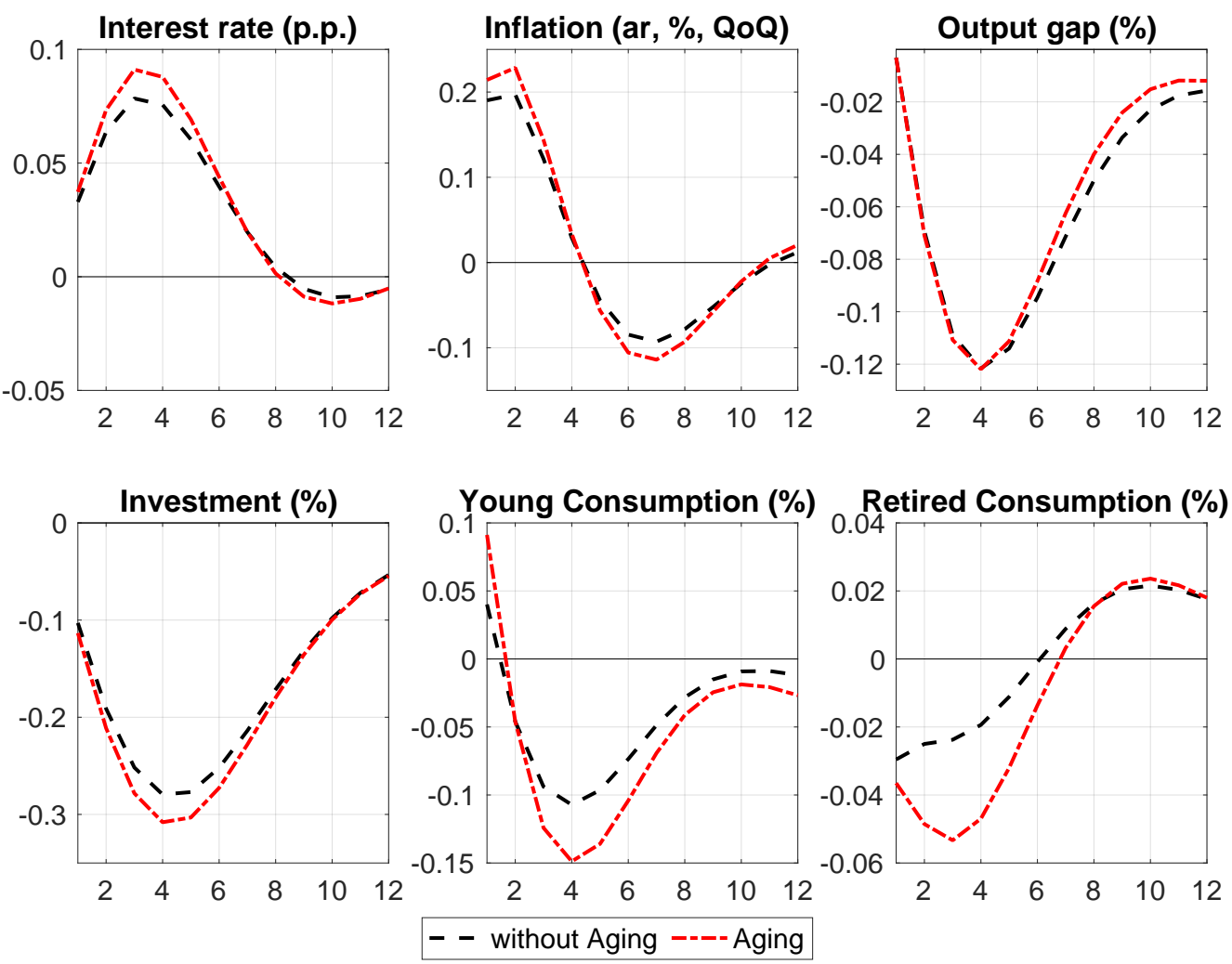

Although the size of the shocks in old and young societies are the same, the immediate impact on nominal and real variables differs. The central bank reacts to offset the positive inflationary expectations (and more negative real interest rate), and discourages households from reallocating future consumption to present consumption. In a young society, both households and firms are 
aware of a possible monetary tightening in the near future, and, due to the expected decline in aggregate demand, the overall increase in inflation is lower than what the shock would imply. At the same time, the young hold more debt, and, at the time of the shock, the temporary negative real interest rate depreciates young households' credit stock. Thus, young households initially increase their consumption. This effect in an old society is larger (in an old society, the young are more indebted than the old); hence, the jump in young consumption is more significant at the beginning. Due to the relatively higher demand in an old society, firms are able to increase their prices by a larger amount. In an old society, the overall inflationary pressure is also higher; the central bank thus needs to be more responsive. This later requires a higher sacrifice (in terms of consumption goods) from the young.

\subsection{Demographic structure and inflation volatility}

In the previous sections, we found that, with aging, the rate of inflation decreases while its volatility increases, and that aging makes monetary policy less effective. Regarding the impact of aging on the rate of inflation, several papers claim that aging leads to a downward pressure on inflation, while some report the opposite. Using data on developed economies (the U.S., the U.K., Germany, France, Japan, and Portugal) ${ }^{10}$ between 1981 and 2018, we find that, from the 1990s, the periods of disinflation correspond with the periods of increases in the old-age dependency ratio (henceforth OADR) (Figure 5). ${ }^{11}$ This is in line with what our model suggests when increasing the old-age dependency ratio in the steady state.

\begin{tabular}{|c|c|c|c|c|c|}
\hline & \multirow[b]{2}{*}{ All obs. } & \multicolumn{4}{|c|}{ Selected intervals } \\
\hline & & 1993-1999 & $2000-2007$ & $2008-2013$ & 2014-2018 \\
\hline mean $\left(C P I^{C O R E}\right)$ & 3.162 & 6.058 & 2.998 & 1.939 & 1.527 \\
\hline$s t d\left(C P I^{C O R E}\right)$ & 0.282 & 0.372 & 0.286 & 0.267 & 0.190 \\
\hline mean $(O A D R)$ & 24.811 & 22.597 & 23.415 & 25.479 & 28.943 \\
\hline std $(Y)$ & 2.758 & 2.486 & 3.190 & 3.152 & 1.862 \\
\hline Number of countries & 34 & 34 & 34 & 34 & 34 \\
\hline
\end{tabular}

Table 3: Descriptive statistics of observed variables: OECD countries between 1993 and 2018

\footnotetext{
${ }^{10}$ Japan is already heavily hit by aging; Portugal will be among the countries with the highest old-age dependency ratio in Europe in a few decades; the US, the UK, Germany and France - although less affected by aging than Japan or Portugal - follow different monetary policy strategies (with France less affected by aging than Germany).

${ }^{11}$ Inflation data comes from the OECD while data on the old-age dependency ratio comes from the UN.
} 
Figure 5: Core inflation and old-age dependency ratio
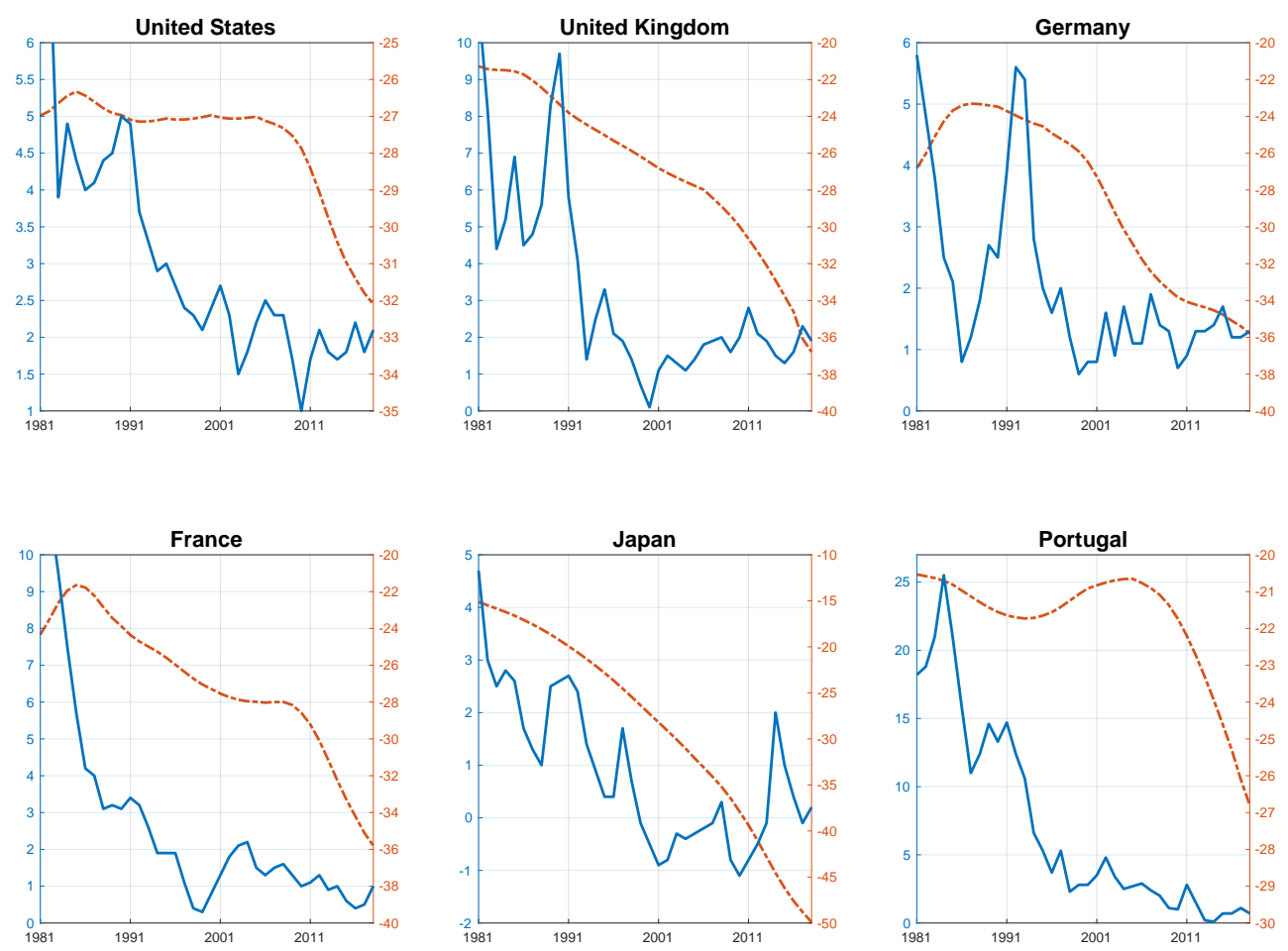

—CPI wo Food \& Energy (\%. YoY) ----Old-Age Dependency Ratio*(-1) (\%)

Regarding the impact of aging on the volatility of inflation, we also test the model's hypothesis using an unbalanced panel dataset on developed OECD countries between 1993 and 2018. Table 3 contains the descriptive statistics of the observed variables. We run a fixed-effect (FE) estimation with country- and time-fixed effects. ${ }^{12}$ For this, we need the time-variant volatility of inflation: first, we remove the trend component of non-food non-energy CPI by an HP-filter with $\lambda=150000$; then, we calculate the yearly average of the standard deviation from the trend, which is interpreted as the time-variant volatility of the cyclical inflation. Next, we run the following FE regression:

$$
\sigma\left(c p i \_c o r e\right)_{i t}=\alpha_{i}+\delta_{t}+\beta \cdot O A D R_{i t}+\gamma \cdot X_{i t}+u_{i t}
$$

where $\sigma\left(c p i \_c o r e\right)_{i t}$ is the standard deviation of non-food non-energy CPI in country $i$ and year $t$, $\alpha_{i}$ is the country-fixed effect, $\delta_{t}$ is the time-fixed effect, $O A D R_{i t}$ is the old-age dependency ratio, $X$ contains other controls (lag, output gap volatility and the year-on-year changes of inflation) ${ }^{13}$,

\footnotetext{
${ }^{12}$ In R with plm package (Croissant and Millo 2008). We calculated and report robust standard errors.

${ }^{13}$ Data on the output gap was downloaded from the OECD.
} 
and $u_{i t}$ denotes the error term.

The estimation results are consistent with the model's intuitions. Namely, all of the estimations suggest a significant and positive relationship between the volatility of inflation and the level of the old-age dependency ratio. Moreover, the impact is sizeable: in our sample, the average inflation volatility is 0.28 , and the old-age dependency ratio increased by 6 percentage point on average over the past 3 decades; the FE regressions suggest that a 6 percentage point increase in the old-age dependency ratio increases inflation volatility by around $0.04-0.11$ cumulatively.

Table 4: Volatility of inflation and old-dependency ratio

\begin{tabular}{|c|c|c|c|c|c|c|}
\hline Models & FE (1) & $\mathrm{FE}(2)$ & FE (3) & FE (4) & FE (5) & FE (6) \\
\hline$\sigma\left(C P I \_C O R E\right)_{i, t-1}$ & & & & $\begin{array}{l}0.218 \\
(0.065)^{* * *}\end{array}$ & $\begin{array}{l}0.207 \\
(0.061)^{* * *}\end{array}$ & $\begin{array}{l}0.104 \\
(0.078)\end{array}$ \\
\hline$O A D R_{i t}$ & $\begin{array}{l}0.014 \\
(0.007)^{*}\end{array}$ & $\begin{array}{l}0.012 \\
(0.007)^{*}\end{array}$ & $\begin{array}{l}0.007 \\
(0.004)^{*}\end{array}$ & $\begin{array}{l}0.014 \\
(0.007)^{* *}\end{array}$ & $\begin{array}{l}0.013 \\
(0.006)^{* *}\end{array}$ & $\begin{array}{l}0.008 \\
(0.004)^{* *}\end{array}$ \\
\hline$\sigma(Y)_{i t}$ & & $\begin{array}{l}0.018 \\
(0.008)^{* *}\end{array}$ & $\begin{array}{l}0.014 \\
(0.007)^{* *}\end{array}$ & & $\begin{array}{l}0.015 \\
(0.007)^{* *}\end{array}$ & $\begin{array}{l}0.011 \\
(0.005)^{* *}\end{array}$ \\
\hline CPI_CORE $E_{i t}$ & & & $\begin{array}{l}0.024 \\
(0.008)^{* * *}\end{array}$ & & & $\begin{array}{l}0.025 \\
(0.008)^{* * *}\end{array}$ \\
\hline Country FE & Yes & Yes & Yes & Yes & Yes & Yes \\
\hline Year FE & Yes & Yes & Yes & Yes & Yes & Yes \\
\hline N. obs & 830 & 830 & 830 & 796 & 796 & 796 \\
\hline N. of countries & 34 & 34 & 34 & 34 & 34 & 34 \\
\hline$R^{2}$ & 0.287 & 0.298 & 0.393 & 0.327 & 0.335 & 0.415 \\
\hline
\end{tabular}

\section{Welfare and Optimal Monetary Policy}

Aging also influences the size of welfare losses. To demonstrate that, first we need to calculate the conditional and unconditional variances of the endogenous variables which are used as inputs in the welfare loss function. The optimal monetary policy rule is the rule which minimizes the loss in social welfare. ${ }^{14}$

\footnotetext{
${ }^{14}$ Calculations are done by the Optimal Simple Rule toolbox of Dynare.
} 


\subsection{The Model's State-Space Form}

Based on the log-linear version of the model, one can express the following forward-looking system of equations which are conditional on the model's steady state, in particular on the demographic structure:

$$
A(\Theta) \xi_{t}=B(\Theta) \xi_{t-1}+C(\Theta) E_{t} \xi_{t+1}+D(\Theta) \varepsilon_{t}
$$

where $\xi$ is the vector of endogenous variables, $\varepsilon$ is the vector of structural shocks with given variances, and $\Theta$ is the set of deep parameters including the steady-state levels of the endogenous variables. $A, B, C$, and $D$ matrices consist of the linearized equations. Using the method of undetermined coefficients, one can express the state-space form of the forward-looking model as follows:

$$
\xi_{t}=\Phi(\Theta) \xi_{t-1}+\Gamma(\Theta) \varepsilon_{t}
$$

Here, $\Phi$ and $\Gamma$ are matrices which are combinations of $A, B, C$, and $D$. Using the state-space form of the model, we can express the conditional covariances as follows:

$$
\Xi_{t}=\Phi(\Theta) \Xi_{t-1} \Phi(\Theta)^{\prime}+\Gamma(\Theta) \Omega \Gamma(\Theta)^{\prime}
$$

Here, $\xi_{t} \xi_{t}^{\prime}=\Xi_{t}$ are conditional covariances of the endogenous variables, while $\varepsilon_{t} \varepsilon_{t}^{\prime}=\Omega$ is a diagonal covariance matrix of the structural shocks.mIterating this equation forward $(t \rightarrow \infty)$, we can express the unconditional covariances as follows:

$$
\operatorname{vec}(\Xi)=(I-\Phi(\Theta) \otimes \Phi(\Theta))^{-1} \operatorname{vec}\left(\Gamma(\Theta) \Omega \Gamma(\Theta)^{\prime}\right)
$$

where $I$ is an identity matrix which has the same size as $\Phi(\Theta) \otimes \Phi(\Theta)$. For the optimal policy exercise with the simulated method of moments, we calibrated the structural shocks in such a way that the model's structural shocks capture the standard deviation of relevant variables of the New Area-Wide model (Christoffel, Coenen, and Warne (2008)); the results are reported in Table $5^{15}$.

\footnotetext{
${ }^{15}$ We calibrated the initial young society version of the model. Each variable is expressed as the percent or percentage point deviation from its steady-state level (the deviation of endogenous variable $x$ is noted by $\hat{x}$ ), the interest rate and inflations are annualized, and the consumption is the sum of the old and young cohort consumption.
} 
Table 5: Calibrated standard deviation of variables and structural shocks

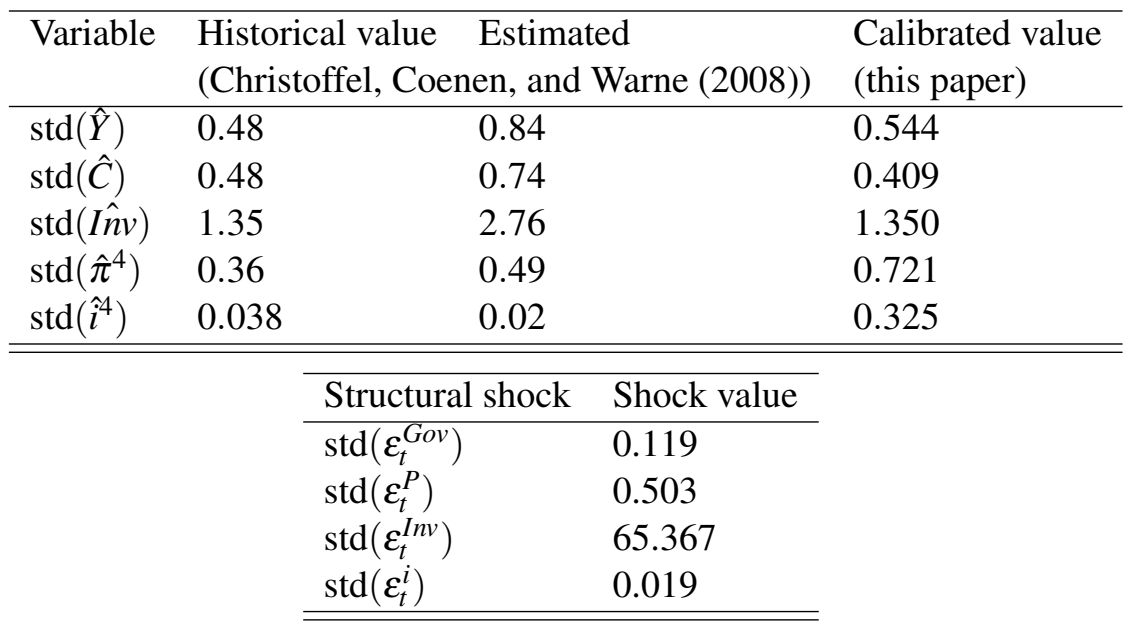

\subsection{Welfare Loss Functions and Monetary Policy Rules}

In order to determine the optimal monetary policy rule, that is, the rule which minimizes the weighted sum of unconditional variances, we first need to specify the social welfare loss function. We have examined two different welfare loss functions.

The presence of overlapping generations and that of the non-representative features of the model make the model very complicated and hard to interpret welfare based on the agents' utility function. Therefore, in the first approach, we assume a simple welfare loss function which assigns a particular weight to the unconditional variances of inflation, output gap, and the difference between today's and yesterday's nominal interest rates. The latter is particularly relevant as it reflects the central bank's concern about financial stability: the central bank does not want to choose a policy which increases the volatility in the financial markets or discourages savings/credits. The weights are taken from Adolfson, Laseen, Linde, and Svensson (2011) and represent the importance of each objective in the central bank's decision-making:

$$
\mathbf{L}=\operatorname{var}\left(\pi_{t}\right)+0.5 \cdot \operatorname{var}\left(\hat{Y}_{t}\right)+0.2 \cdot \operatorname{var}\left(i_{t}-i_{t-1}\right)
$$

Here, $\hat{Y}$ is the output gap defined as the deviation of GDP from its flexible price level.

In the second experiment, we derive the second-order approximation of the utility function and assume that the central bank in different stages of the population aging sets a policy rule which 
minimizes the weighted average of the two utilities ${ }^{16}$ :

$$
\mathscr{W}_{t}=s_{t}^{Y} \tilde{U}_{t}^{Y}(i)+\left(1-s_{t}^{Y}\right) \tilde{U}_{t}^{O}(i)
$$

where the utilities are expressed as follows:

$$
\begin{aligned}
\tilde{U}_{t}^{O}(i) & =-(1-\gamma) U^{O}(i) \frac{\gamma-1}{2} \hat{C}_{t}^{O}(i)^{2} \\
\tilde{U}_{t}^{Y}(i) & =-\sigma(1-\gamma) U^{Y}(i) \frac{\sigma(\gamma-1)}{2} \hat{C}_{t}^{Y}(i)^{2}+ \\
& -(1-\sigma)(1-\gamma) U^{Y}(i) \frac{L(i)}{1-L(i)}\left(\frac{\varphi_{P}}{2 \lambda_{P}}\left(\pi_{t}-\gamma_{P} \pi_{t-1}\right)^{2}+\frac{\varphi_{W}}{2 \lambda_{V}}\left(\pi_{t}^{V}-\gamma_{P} \pi_{t-1}^{V}\right)^{2}\right)+ \\
& -(1-\sigma)(1-\gamma) U^{Y}(i) \frac{L(i)}{1-L(i)} \frac{1}{2}\left(1+(\sigma+\gamma(1-\sigma)) \frac{L(i)}{1-L(i)}\right) \hat{L}_{t}(i)^{2} \\
& -\sigma(1-\sigma)(1-\gamma)^{2} U^{Y}(i) \frac{L(i)}{1-L(i)} \hat{C}_{t}^{Y}(i) \hat{L}_{t}(i)
\end{aligned}
$$

Here, the approximated levels of individual consumption and individual labor are given by:

$$
\begin{aligned}
C_{t}^{Y}(i) & =\frac{C_{t}^{Y}}{N_{t}^{Y}}=\frac{\tilde{C}_{t}^{Y}}{s_{t}^{Y}} \\
L_{t}(i) & =\frac{L_{t}}{N_{t}^{Y}}=\frac{\tilde{L}_{t}}{s_{t}^{Y}} \\
C_{t}^{O}(i) & =\frac{C_{t}^{O}}{N_{t}^{O}}=\frac{\tilde{C}_{t}^{O}}{1-s_{t}^{Y}}
\end{aligned}
$$

Several monetary policy rules are examined: (i) the pure inflation targeting rule (including a forward-looking IT), (ii) flexible inflation targeting with output or employment reaction (including a forward-looking version as well), (iii) price level targeting, and (iv) nominal GDP or nominal wage bill targeting. There are significant differences between the two welfare loss functions, namely, the utility-based function does not contain output gap. However, the variation in GDP mostly depends on the level of employment, so the optimized rules should be different in order to have reasonable reactions and the procedure can find the optimum of the likelihood functions. Therefore, in the flexible inflation targeting rule using the utility-based welfare loss function, we assume the employment gap instead of output gap, and, following the same idea, the nominal wage

\footnotetext{
${ }^{16}$ The detailed derivation of the utility-based welfare loss function can be found in the Appendix.
} 
bill instead of the nominal GDP. Formally, the rules are defined as follows:

$i_{t}=\rho i_{t-1}+(1-\rho) \tilde{r}_{t}^{n}+(1-\rho) \begin{cases}\phi_{\pi_{t}} \pi_{t} & \text { Pure IT } \\ \phi_{E_{t}} \pi_{t+1} E_{t} \pi_{t+1} & \text { Pure IT \& Fwd } \\ \phi_{\pi_{t}} \pi_{t}+\phi_{\hat{Y}_{t}} \hat{Y}_{t} \text { or } \phi_{\hat{L}_{t}} \hat{L}_{t} & \text { Flex. IT } \\ \phi_{E_{t}} \pi_{t+1} \pi_{t+1}+\phi_{\widehat{Y}_{t}} \hat{Y}_{t} \text { or } \phi_{\hat{L}_{t}} \hat{L}_{t} & \text { Flex. IT \& Fwd } \\ \phi_{\hat{P}_{t}} \hat{P}_{t} & \text { Price level targeting } \\ \phi_{\widehat{P_{t} Y_{t}}} \widehat{P_{t} Y_{t}} \text { or } \phi_{\widehat{V_{t} L_{t}} \widehat{V_{t} L_{t}}} & \text { Nominal GDP or wage bill targeting }\end{cases}$

Conditional on the selected rules and the demographic structure, we look for the reaction parameters which minimize the total welfare losses described above.

\subsection{Optimal Monetary Policy}

First of all, we compare welfare losses with different demographic structures but with the same non-optimal monetary policy rule (same non-optimal parameters) and show how the increase in the old-age dependency ratio influences them (Table 6 -7). Table 8 shows the changes of the weights in the utility-based welfare loss function. The old-age dependency ratio is a function of the retirement probability, the survival probability, and the net fertility rate. During the aging process, the latter two are assumed to change; in the table below, we present the cases where the two probabilities change at the same time (alternative combinations of the two rates and their welfare values can be found in the Appendix). As aging becomes more prevalent, that is, the old-age dependency ratio increases, the volatility of the inflation rate and that of the interest rate increase. Despite the increasing volatility of young consumption and employment, the decreasing weight of young households generates lower output gap volatility. Initial losses are normalized to $s=$ 0.2 , where $s$ denotes the old-age dependency ratio and the optimal values are always normalized by their own initial loss values. Regardless of the population aging, the nominal variables have significantly larger weights in the utility-based loss function. This implies that the central bank should react strongly to nominal variables if it wishes to maximize utility-based welfare losses. 
Table 6: Old-age dependency ratios and welfare levels with the baseline monetary policy rules when using the ad hoc welfare loss function

\begin{tabular}{|l|r|r|r|r|}
\hline & \multicolumn{4}{|c|}{ Old-age dependency ratios } \\
\hline & $s=0.20$ & $s=0.36$ & $s=0.49$ & $s=0.60$ \\
\hline \hline Initial losses & 1.00 & 0.98 & 0.98 & 0.99 \\
\hline \hline Inflation: & 0.18 & 0.20 & 0.22 & 0.24 \\
\hline Output gap: & 0.82 & 0.78 & 0.76 & 0.74 \\
\hline Interest rate: & 0.00 & 0.00 & 0.00 & 0.00 \\
\hline
\end{tabular}

Table 7: Old-age dependency ratios and welfare levels with the baseline monetary policy rules when using the utility-based welfare loss function

\begin{tabular}{|l|r|r|r|r|}
\hline & \multicolumn{4}{|c|}{ Old-age dependency ratios } \\
\hline & $s=0.20$ & $s=0.36$ & $s=0.49$ & $s=0.60$ \\
\hline \hline Initial losses & 1.00 & 1.36 & 2.02 & 3.20 \\
\hline \hline Inflation: & 0.14 & 0.18 & 0.24 & 0.34 \\
\hline Wage Inflation: & 0.25 & 0.40 & 0.68 & 1.22 \\
\hline Young Consumption: & 0.06 & 0.08 & 0.11 & 0.18 \\
\hline Old Consumption: & 0.00 & 0.00 & 0.01 & 0.02 \\
\hline Labor: & 0.58 & 0.75 & 1.05 & 1.55 \\
\hline Young Cons. Labor cov: & -0.04 & -0.05 & -0.07 & -0.09 \\
\hline
\end{tabular}

Table 8: Old-age dependency ratios and age-dependent weights of the utility-based welfare loss function

\begin{tabular}{|l|r|r|r|r|}
\hline & \multicolumn{4}{|c|}{ Old-age dependency ratios } \\
\hline & $s=0.20$ & $s=0.36$ & $s=0.49$ & $s=0.60$ \\
\hline \hline Inflation: & 11.00 & 12.68 & 15.54 & 19.87 \\
\hline Wage Inflation: & 12.36 & 14.24 & 17.46 & 22.32 \\
\hline Young Consumption: & 0.27 & 0.26 & 0.27 & 0.29 \\
\hline Old Consumption: & 0.06 & 0.10 & 0.12 & 0.13 \\
\hline Labor: & 0.77 & 1.01 & 1.41 & 2.08 \\
\hline Young Cons. Labor cov: & -0.35 & -0.41 & -0.50 & -0.64 \\
\hline
\end{tabular}

Next, optimal monetary policy reaction functions (Table 9 - 10) are explored. Thus, for any given OADR, we calculate the minimum social welfare loss with the different monetary-policy regimes and the related monetary-policy rule parameters. Our main finding is that in a younger society, the flexible inflation targeting regime, with a strong reaction to expected inflation and a somewhat weaker reaction to the output gap, is the most effective rule, that is, the loss-minimizing option, if the monetary policy minimizes the ad hoc welfare loss function. Under the utility-based welfare loss function, the flexible inflation targeting performs well. Nonetheless, nominal wage bill targeting is the best option, although the improvement in welfare compared to flexible inflation targeting is not significant. In grayer societies, however, although the flexible inflation targeting regime could be one of the favorable options, the central bank should react mildly to the output gap or employment gap and more strongly to the level of inflation. 
Table 9: Old-age dependency ratios and optimal reaction parameters in six monetary policy regimes when using the ad hoc welfare loss function

\begin{tabular}{|l|l|r|r|r|r|}
\hline & & \multicolumn{4}{|c|}{ Old-age dependency ratios } \\
\hline & & $s=0.20$ & $s=0.36$ & $s=0.49$ & $s=0.60$ \\
\hline \hline \multirow{2}{*}{ Initial rule } & Initial loss & 1.00 & 0.98 & 0.98 & 0.99 \\
& $\phi_{\pi_{t}}$ & 1.70 & 1.70 & 1.70 & 1.70 \\
\hline \hline \multirow{2}{*}{ Pure IT } & Optimized loss & 0.99 & 0.98 & 0.97 & 0.95 \\
& $\phi_{\pi_{t}}$ & 2.34 & 2.59 & 2.96 & 3.50 \\
\hline \hline \multirow{2}{*}{ Pure IT \& Fwd } & Optimized loss & 0.92 & 0.93 & 0.92 & 0.92 \\
& $\phi_{E_{t} \pi_{t+1}}$ & 3.86 & 4.26 & 4.83 & 5.64 \\
\hline \hline \multirow{3}{*}{ Flex. IT } & Optimized loss & 0.91 & 0.91 & 0.91 & 0.91 \\
& $\phi_{\pi_{t}}$ & 4.40 & 4.67 & 5.12 & 5.81 \\
& $\phi_{\hat{Y}_{t}}$ & 0.86 & 0.86 & 0.88 & 0.93 \\
\hline \hline \multirow{3}{*}{ Flex. IT \& Fwd } & Optimized loss & 0.89 & 0.90 & 0.90 & 0.89 \\
& $\phi_{E_{t} \pi_{t+1}}$ & 5.19 & 5.53 & 6.05 & 6.83 \\
& $\phi_{\hat{Y}_{t}}$ & 0.65 & 0.62 & 0.59 & 0.56 \\
\hline \hline \multirow{2}{*}{ Price level targ. } & Optimized loss & 1.10 & 1.10 & 1.09 & 1.07 \\
& $\phi_{\hat{P}_{t}}$ & 0.08 & 0.14 & 0.23 & 0.39 \\
\hline \hline \multirow{2}{*}{ Nominal GDP targ. } & Optimized loss & 0.94 & 0.94 & 0.93 & 0.92 \\
& $\phi_{\widehat{P_{t} Y_{t}}}$ & 32.46 & 36.89 & 47.49 & 62.52 \\
\hline
\end{tabular}

The nominal wage bill targeting rule is the most effective rule under utility maximization. To understand the reasons for this, we should check the components of nominal GDP and nominal wage bill targeting separately. Nominal GDP targeting is basically a combination of price and nominal wage level targeting and output gap or employment gap stabilization, meaning that second-round effects on aggregate demand are also taken into account. Price level targeting generates higher welfare losses than nominal GDP targeting does. While price level targeting is quite hawkish, the central bank tolerates a larger economic sacrifice to achieve price-level stability. This kind of dual-mandate, like nominal GDP targeting or wage bill targeting, guarantees that the welfare loss is minimized when both the price level and the output gap or employment gap vary as little as possible. However, the reaction to the nominal wage bill decreases in aging societies; this decline is consistent with the milder reaction to the employment gap in other rules under utility-based welfare maximization. Due to the decreasing Frisch elasticity in aging societies, for the same amount of labor increase, wages and inflation increase more. Thus, the monetary policy reacts less to the employment gap so as not to contribute to the higher volatility of the nominal variables. 
Table 10: Old-age dependency ratios and optimal reaction parameters in six monetary policy regimes by the utility-based welfare loss function

\begin{tabular}{|l|l|r|r|r|r|}
\hline & & \multicolumn{4}{|c|}{ Old-age dependency ratios } \\
\hline & & $s=0.20$ & $s=0.36$ & $s=0.49$ & $s=0.60$ \\
\hline \hline \multirow{2}{*}{ Initial rule } & Initial loss & 1.00 & 1.36 & 2.02 & 3.20 \\
& $\phi_{\pi_{t}}$ & 1.70 & 1.70 & 1.70 & 1.70 \\
\hline \hline \multirow{2}{*}{ Pure IT } & Optimized loss & 0.32 & 0.29 & 0.28 & 0.31 \\
& $\phi_{\pi_{t}}$ & 30.57 & 32.74 & 34.08 & 31.93 \\
\hline \hline \multirow{2}{*}{ Pure IT \& Fwd } & Optimized loss & 0.28 & 0.26 & 0.16 & 0.16 \\
& $\phi_{E_{t}} \pi_{t+1}$ & 51.26 & 54.19 & 55.31 & 50.12 \\
\hline \multirow{3}{*}{ Flex. IT } & Optimized loss & 0.25 & 0.24 & 0.24 & 0.28 \\
& $\phi_{\pi_{t}}$ & 11.13 & 15.02 & 17.43 & 17.10 \\
& $\phi_{\hat{L}_{t}}$ & 17.09 & 15.25 & 11.09 & 6.52 \\
\hline \multirow{3}{*}{ Flex. IT \& Fwd } & Optimized loss & 0.25 & 0.23 & 0.24 & 0.27 \\
& $\phi_{E_{t}} \pi_{t+1}$ & 14.71 & 19.66 & 24.16 & 24.84 \\
& $\phi_{\hat{L}_{t}}$ & 15.92 & 14.38 & 11.18 & 6.90 \\
\hline \hline \multirow{2}{*}{ Price level targ. } & Optimized loss & 0.45 & 0.42 & 0.40 & 0.41 \\
& $\phi_{\hat{P}_{t}}$ & 13.83 & 15.89 & 17.73 & 17.47 \\
\hline \hline \multirow{2}{*}{ Nominal Wage Bill targ. } & Optimized loss & 0.24 & 0.22 & 0.22 & 0.27 \\
& $\phi_{\widehat{V}_{t} L_{t}}$ & 31.73 & 31.70 & 25.48 & 15.29 \\
\hline
\end{tabular}

\section{Conclusion}

In this paper, we explored the monetary consequences of aging in a multi-period DGE model with OLG agents. Specifically, we examined how aging affects (i) inflation in the longer term, (ii) the short-run cyclical behavior of the economy, including monetary policy transmission, and (iii) optimal monetary policy rules. The stylized facts and empirical estimations were consistent with the message of the model, and we found that the rate of inflation decreases, while its volatility increases with aging, aging makes monetary policy less effective, and an IT regime with a high inflation reaction is optimal in the case of high, but still reasonable, OADRs.

In Section 6, we reported that the same size shock causes higher inflation volatility in an older society. Not only inflation, but the macroeconomy in general, reacts differently to shocks - including monetary policy shocks. The transmission of monetary policy changes, and monetary policy becomes less effective. The most important channel is that as agents live longer and their planning horizon becomes longer, their savings position changes: the young are willing to borrow more, while the retired accumulate more savings to guarantee their consumption over a longer time horizon. Hence, when the interest rate changes, it has different implications for the young and the old: higher interest rates imply an extra cost for the young, who are indebted, while the old generate more income. Additionally, the young and the old also make different consumption-savings 
decisions (as the old are more patient than the young), and there are labor market implications as well (the labor market becomes tighter and real wages react more as the labor force shrinks). In Section 7, we discussed that aging, via higher inflation, also increases social welfare loss. To avoid that, central banks with inflation-targeting regimes should react more strongly to nominal variables: they should increase the nominal interest rate by a larger amount, given the same size shock. Under some circumstances, nominal GDP targeting or nominal wage bill targeting is a more effective rule than the common practice of inflation targeting. Aging, a clear concern for fiscal economists, ought to be a concern for central bankers as well.

To the best of our knowledge, our paper is the first which (i) estimates the impact of aging on the volatility of inflation, (ii) explores the impact of aging on the short-run cyclical behavior of the macroeconomy, including monetary policy transmission, in an aged society, using a multi-period dynamic general equilibrium model with overlapping generations, and (iii) examines optimal monetary policy strategies in the presence of aging. Given the scarce literature in this field, we call for more research to better understand the implications of aging for central banks, central bankers, and the elderly. 


\section{A.1 Appendix: List of Non-Linear Equations ${ }^{17}$}

Demography:

$$
\begin{aligned}
& s_{t}=\frac{\left(1-\omega_{t-1}^{O}\right)}{\left(1-\omega_{t-1}^{Y}+n_{t}\right)} s_{t-1}+\frac{\omega_{t-1}^{Y}}{\left(1-\omega_{t-1}^{Y}+n_{t}\right)} \\
& s_{t}^{Y}=\frac{1}{1+s_{t}} \\
& 1+g_{t}^{N, Y}=1-\omega_{t-1}^{Y}+n_{t} \\
& 1+g_{t}^{N, O}=\left(1-\omega_{t-1}^{O}\right)+\frac{\omega_{t-1}^{Y}}{s_{t-1}} \\
& 1+g_{t}^{N}=\left(1+g_{t}^{N, Y}\right) \frac{1+s_{t}}{1+s_{t-1}}
\end{aligned}
$$

Overlapping generations:

$$
\begin{aligned}
& \tilde{C}_{t}^{O}=M P C_{t}^{O} \tilde{T R_{t}} \Omega_{t}^{O}+M P C_{t}^{O} \frac{\left(1+r_{t-1}\right)}{1+g_{t}^{N}}\left(\omega_{t-1}^{Y} \tilde{B}_{t-1}^{Y}+\tilde{B}_{t-1}^{O}\right) \\
& \frac{1}{M P C_{t}^{O}}=1+\left(1-\omega_{t}^{O}\right)\left(1+r_{t}\right)^{\frac{1}{\gamma}-1} E_{t} \beta^{\frac{1}{\gamma}} \frac{1}{M P C_{t+1}^{O}} \\
& \Omega_{t}^{O}=1+E_{t} \frac{1-\omega_{t}^{O}}{1+r_{t}} \Omega_{t+1}^{O} \\
& \tilde{C}_{t}^{Y}=M P C_{t}^{Y} I \tilde{n} c_{t}^{Y}+M P C_{t}^{Y} \frac{\left(1+r_{t-1}\right)\left(1-\omega_{t-1}^{Y}\right)}{1+g_{t}^{N}} \tilde{B}_{t-1}^{Y} \\
& \frac{\tilde{C}_{t}^{Y}}{s_{t}^{Y}-\tilde{L}_{t}}=\frac{\sigma}{1-\sigma} w_{t} \\
& \Lambda_{t}^{Y}=E_{t} \beta^{\frac{1}{\gamma}}\left(\frac{w_{t+1}}{w_{t}}\right)^{(1-\sigma)\left(1-\frac{1}{\gamma}\right)} \\
& \Lambda_{t}^{Y O}=E_{t}\left(\frac{\beta}{\sigma}\right)^{\frac{1}{\gamma}}\left(\frac{1}{\frac{\sigma}{1-\sigma} w_{t}}\right)^{(1-\sigma)\left(1-\frac{1}{\gamma}\right)} \\
& \frac{1}{M P C_{t}^{Y}}=\frac{1}{\sigma}+\left(1+r_{t}\right)^{\frac{1}{\gamma}-1} E_{t}\left(\left(1-\omega_{t}^{Y}\right) \Lambda_{t}^{Y} \frac{1}{M P C_{t+1}^{Y}}+\omega_{t}^{Y} \Lambda_{t}^{Y O} \frac{1}{M P C_{t+1}^{O}}\right) \\
& \tilde{I n} c_{t}^{Y}=w_{t} s_{t}^{Y}+\operatorname{Proffit}_{t}-\tilde{\operatorname{Ta}} x_{t}+E_{t} \frac{1+g_{t+1}}{1+r_{t}} E_{t} \tilde{T R_{t+1}^{Y O}} \Omega_{t+1}^{O}+E_{t} \frac{1+s_{t+1}}{1+s_{t}} \frac{1-\omega_{t}^{Y}}{1+r_{t}} \tilde{I} c_{t+1}^{Y} \\
& \tilde{C}_{t}^{Y}+\tilde{B}_{t}^{Y}=w_{t} \tilde{L}_{t}+\text { Profit }_{t}-\tilde{\operatorname{Tax}_{t}}+\frac{\left(1+r_{t-1}\right)}{1+g_{t}^{N}}\left(1-\omega_{t-1}^{Y}\right) \tilde{B}_{t-1}^{Y}
\end{aligned}
$$

\footnotetext{
${ }^{17}$ The quantities are normalized by the total population number $N_{t}$.
} 
Firms:

$$
\begin{aligned}
& p_{t}^{*}=\frac{\varphi}{\varphi-1} \frac{\tilde{\mathscr{Z}}_{t}^{1}}{\tilde{\mathscr{Z}}_{t}^{2}} \\
& \tilde{\mathscr{Z}}_{t}^{1}=p_{t}^{*-\varphi} \tilde{Y}_{t} m c_{t}+E_{t}\left(\frac{p_{t}^{*}}{p_{t+1}^{*}} \frac{\left(1+\pi_{t}\right)^{\gamma_{P}}}{1+\pi_{t+1}}\right)^{-\varphi} \omega^{P}\left(1-\omega_{t}^{Y}\right) \frac{1+\pi_{t+1}}{1+i_{t}}\left(1+g_{t+1}^{N}\right) \tilde{\mathscr{Z}}_{t+1}^{1} \\
& \tilde{\mathscr{Z}}_{t}^{2}=p_{t}^{*-\varphi} \tilde{Y}_{t}+E_{t}\left(\frac{p_{t}^{*}}{p_{t+1}^{*}} \frac{\left(1+\pi_{t}\right)^{\gamma_{P}}}{1+\pi_{t+1}}\right)^{-\varphi}\left(1+\pi_{t}\right)^{\gamma_{P}} \omega^{P}\left(1-\omega_{t}^{Y}\right) \frac{1+g_{t+1}^{N}}{1+i_{t}} \mathscr{Z}_{t+1}^{2} \\
& 1=\left(1-\omega_{P}\right) p_{t}^{* 1-\varphi}+\omega_{P}\left(\frac{\left(1+\pi_{t-1}\right)^{\gamma_{P}}}{1+\pi_{t}}\right)^{1-\varphi} \\
& m c_{t}=\frac{e^{\varepsilon_{t}^{P}}}{A_{t}}\left(\frac{r_{t}^{K}}{\alpha}\right)^{\alpha}\left(\frac{w_{t}}{1-\alpha}\right)^{1-\alpha} \\
& \tilde{K}_{t-1} \frac{1}{1+g_{t}^{N}}=\alpha \frac{m c_{t}}{r_{t}^{K}} \tilde{Y}_{t} \\
& \tilde{L}_{t}=(1-\alpha) \frac{m c_{t}}{w_{t}} \tilde{Y}_{t} \\
& \operatorname{profit}_{t}=\tilde{Y}_{t}-\tilde{I n} v_{t}-w_{t} \tilde{L}_{t} \\
& \left(1-\omega_{t}^{Y}\right) E_{t}\left(r_{t+1}^{K}+Q_{t+1}(1-\delta)\right)=Q_{t}\left(1+r_{t}\right) \\
& 1=Q_{t}\left(1-S\left(\frac{\operatorname{In} v_{t}}{\operatorname{In} v_{t-1}}\right)-S^{\prime}\left(\frac{I \tilde{n} v_{t}}{\operatorname{In} v_{t-1}}\right) \frac{I \tilde{n} v_{t}}{\operatorname{In} v_{t-1}}\right)+\frac{1}{1+r_{t}} Q_{t+1} S^{\prime}\left(\frac{\tilde{I} \tilde{n} v_{t+1}}{\operatorname{In} v_{t}}\right)\left(\frac{\operatorname{In} v_{t+1}}{\operatorname{In} v_{t}}\right)^{2}(97) \\
& \operatorname{Inv_{t}}\left(1-S\left(\frac{\operatorname{Inv_{t}}}{\operatorname{In\tilde {v}_{t-1}}}\right)\right)=\tilde{K}_{t}-(1-\delta) \frac{K_{t-1}^{\tilde{1}}}{1+g_{t}^{N}} \\
& S\left(\frac{\tilde{I} \tilde{n} v_{t}}{\operatorname{In} v_{t-1}}\right)=\frac{\phi_{I n v}\left(1+\xi_{t}^{I n v}\right)}{2}\left(\frac{I \tilde{n} v_{t}}{\operatorname{In} v_{t-1}}-1\right)^{2} \\
& S^{\prime}\left(\frac{\operatorname{In} v_{t}}{\operatorname{In} v_{t-1}}\right)=\phi_{I n v}\left(1+\xi_{t}^{I n v}\right)\left(\frac{I \tilde{n} v_{t}}{\operatorname{In} v_{t-1}}-1\right)^{2}
\end{aligned}
$$

Labor union:

$$
\begin{aligned}
& v_{t}^{*}=\frac{\varphi_{V}}{\varphi_{V}-1} \frac{\tilde{\mathscr{W}}_{t}^{1}}{\tilde{\mathscr{W}}_{t}^{2}} \\
& \left.\tilde{\mathscr{W}}_{t}^{1}=\left(\frac{v_{t}^{*}}{v_{t}}\right)^{-\varphi_{W}} \tilde{L}_{t} w_{t}+E_{t}\left(\frac{v_{t}^{*}}{v_{t+1}^{*}} \frac{\left(1+\pi_{t}^{V}\right)^{\gamma}}{1+\pi_{t+1}^{V}}\right)^{-\varphi_{V}} \frac{\omega_{V}\left(1-\omega_{t}^{Y}\right)\left(1+\pi_{t+1}\right)}{1+i_{t}}\left(1+g_{t+1}^{N}\right) \tilde{\mathscr{W}}_{t} 1 \hat{q} 2\right) \\
& \tilde{\mathscr{W}}_{t}^{2}=\left(\frac{v_{t}^{*}}{v_{t}}\right)^{-\varphi_{V}} \tilde{L}_{t}+E_{t}\left(\frac{v_{t}^{*}}{v_{t+1}^{*}} \frac{\left(1+\pi_{t}^{V}\right)^{\gamma_{V}}}{1+\pi_{t+1}^{V}}\right)^{-\varphi_{V}} \frac{\omega_{V}\left(1-\omega_{t}^{Y}\right)\left(1+\pi_{t}^{V}\right)^{\gamma}}{1+i_{t}}\left(1+g_{t+1}^{N}\right) \tilde{\mathscr{W}}_{t}^{2}(103) \\
& 1=\left(1-\omega_{V}\right)\left(\frac{v_{t}^{*}}{v_{t}}\right)^{1-\varphi_{V}}+\omega_{V}\left(\frac{\left(1+\pi_{t-1}^{V}\right)^{\gamma_{V}}}{1+\pi_{t}^{V}}\right)^{1-\varphi_{V}} \\
& 1+\pi_{t}^{V}=\left(1+\pi_{t}\right) \frac{v_{t}}{v_{t-1}}
\end{aligned}
$$


Tax system:

$$
\begin{aligned}
& \tilde{D e b t_{t}}+\tilde{T a x_{t}}=\tilde{T R_{t}}+\tilde{G o v_{t}}+\left(1+r_{t-1}\right) \tilde{D e} b t_{t-1} \\
& \tilde{T a} x_{t}=\tilde{T R_{t}}+\tilde{G o v_{t}}+\left(1+r_{t-1}\right) \tilde{D e} b t_{t-1}-\left\{\frac{D e b t}{Y}\right\}^{\text {Target }} \tilde{Y}_{t}
\end{aligned}
$$

PAYG pension system:

$$
\begin{aligned}
& \tilde{T R}_{t}^{Y O}=v_{t} \frac{\omega_{t-1}^{Y}}{1+g_{t}^{N}} w_{t-1} \tilde{L}_{t-1} \\
& \tilde{T R_{t}}=\tilde{T R_{t}^{Y O}}+\frac{\left(1-\omega_{t-1}^{O}\right)}{1+g_{t}^{N}} \tilde{T R_{t-1}}
\end{aligned}
$$

Monetary policy:

$$
\begin{aligned}
& 1+i_{t}=\left(1+i_{t-1}\right)^{\rho_{i}}\left(\left(1+r_{t}^{n}\right)\left(1+\pi_{t}\right)^{\phi_{\pi}}\right)^{1-\rho_{i}} e^{\varepsilon_{t}^{i}} \\
& 1+i_{t}=E_{t}\left(1+r_{t}\right)\left(1+\pi_{t+1}\right)
\end{aligned}
$$

Market clearing:

$$
\begin{aligned}
& \tilde{D e} b t_{t}=\tilde{B_{t}^{Y}}+\tilde{B_{t}^{O}} \\
& \tilde{Y}_{t}=\tilde{C}_{t}^{Y}+\tilde{C}_{t}^{O}+\tilde{I n} v_{t}+\tilde{G o} v_{t}
\end{aligned}
$$




\section{A.2 Appendix: Second-order approximation of utility based welfare loss function}

In this appendix, we derive the second order approximation of the households' utility function. The social welfare function is defined as the weighted average of contemporaneous cohort level welfare functions. The central bank minimizes the population weighted average of utilities:

$$
\mathscr{W}_{t}=s_{t}^{Y} \tilde{U}_{t}^{Y}(i)+\left(1-s_{t}^{Y}\right) \tilde{U}_{t}^{O}(i)
$$

where the $\mathscr{W}_{t}$ denotes the social welfare function, $\tilde{U}_{t}^{Y}(i)$ and $\tilde{U}_{t}^{O}(i)$ are the approximated welfare of the young and retired households, respectively.

\section{Retired generation}

'Retired' agent $i$ of retired cohort is one individual:

$$
U_{t}^{O}(i)=\frac{1}{1-\gamma}\left\{C_{t}^{O}(i)\right\}^{1-\gamma}
$$

Second-order approximation:

$$
\begin{aligned}
& U_{t}^{O}(i)=U^{O}(i)+U_{C^{O}}^{O}\left(C_{t}^{O}(i)-C^{O}(i)\right)+\frac{1}{2} U_{C^{O}(i), C^{O}(i)}^{O}\left(C_{t}^{O}(i)-C^{O}(i)\right)^{2}+o(2) \\
& U_{C^{O}(i)}^{O}=C^{O}(i) \\
& U_{C^{O}(i), C^{O}(i)}^{O}=-\gamma C^{O}(i)^{-\gamma-1}
\end{aligned}
$$

or

$$
U_{t}^{O}(i)=U^{O}(i)+U_{C^{o}(i)}^{O} C^{O}(i) \frac{C_{t}^{O}(i)-C^{O}(i)}{C^{O}(i)}+\frac{1}{2} U_{C^{O}(i), C^{O}(i)}^{O} C^{O}(i)^{2}\left(\frac{C_{t}^{O}(i)-C^{O}(i)}{C^{O}(i)}\right)^{2}
$$

We can also express the second-order approximation of consumption changes:

$$
\frac{C_{t}^{O}(i)-C^{O}}{C^{O}}=\hat{C}_{t}^{O}(i)+\frac{1}{2} \hat{C}_{t}^{O}(i)^{2}+o(3)
$$


Putting them together:

$$
\begin{aligned}
& U_{t}^{O}(i)=U^{O}(i)+U_{C^{O}(i)}^{O} C^{O}(i)\left(\hat{C}_{t}^{O}(i)+\frac{1}{2} \hat{C}_{t}^{O}(i)^{2}+\frac{1}{2} \frac{U_{C^{O}(i), C^{O}(i)}^{O} C^{O}(i)^{2}}{U_{C^{O}(i)}^{O} C^{O}(i)}\left(\frac{C_{t}^{O}(i)-C^{O}(i)}{C^{O}(i)}\right)^{2}\right) \\
& U_{t}^{O}(i)=U^{O}(i)+U_{C^{O}(i)}^{O} C^{O}(i)\left(\hat{C}_{t}^{O}(i)+\frac{1-\gamma}{2} \hat{C}_{t}^{O}(i)^{2}\right)
\end{aligned}
$$

where $\hat{C}_{t}^{O}(i)^{2}$ are the unconditional variance of the retired households consumption, we assume that the monetary policy minimizes the variance of the variable:

$$
\tilde{U}_{t}^{O}(i)=-(1-\gamma) U^{O}(i) \frac{\gamma-1}{2} \hat{C}_{t}^{O}(i)^{2}
$$

As a simplification, we assume that the individual consumption is equal with the average consumption of the pensioners:

$$
C_{t}^{O}(i) \approx \frac{C_{t}^{O}}{N_{t}^{O}}=\frac{\tilde{C}_{t}^{O}}{1-s_{t}^{Y}}
$$

\section{Young generation}

The second-order approximation of young generation's utility function can be given as

$$
\begin{aligned}
U_{t}^{Y}(i) & =U^{Y}(i)+U_{C^{Y}(i)}^{Y}\left(C_{t}^{Y}(i)-C^{Y}(i)\right)+\frac{1}{2} U_{C^{Y}(i), C^{Y}(i)}^{Y}\left(C_{t}^{Y}(i)-C^{Y}(i)\right)^{2}+ \\
& +U_{L(i)}^{Y}\left(L_{t}(i)-L(i)\right)+\frac{1}{2} U_{L(i), L(i)}^{Y}\left(L_{t}(i)-L(i)\right)^{2} \\
& +U_{C^{Y}, L(i)}^{Y}\left(C_{t}^{Y}(i)-C^{Y}(i)\right)\left(L_{t}(i)-L(i)\right)
\end{aligned}
$$

As a first step we need to calculate the derivatives of the following utility function:

$$
U^{Y}(i)=\frac{1}{1-\gamma}\left\{C^{Y}(i)^{\sigma}(1-L(i))^{1-\sigma}\right\}^{1-\gamma}
$$

The first partial derivative of consumption:

$$
\begin{aligned}
U_{C^{Y}(i)}^{Y} & =\left\{C^{Y}(i)^{\sigma}(1-L(i))^{(1-\sigma)}\right\}^{-\gamma} \sigma C^{Y}(i)^{\sigma-1}(1-L(i))^{(1-\sigma)} \\
& =\sigma C^{Y}(i)^{\sigma-1-\gamma \sigma}(1-L(i))^{(1-\sigma)(1-\gamma)} \\
& =\sigma(1-\gamma) \frac{U^{Y}(i)}{C^{Y}(i)}
\end{aligned}
$$


The second partial derivative of consumption:

$$
\begin{aligned}
U_{C^{Y}(i), C^{Y}(i)}^{Y} & =\sigma(\sigma-1-\gamma \sigma) C^{Y}(i)^{\sigma-2-\gamma \sigma}(1-L(i))^{(1-\sigma)(1-\gamma)} \\
& =\sigma(\sigma-1-\gamma \sigma)(1-\gamma) \frac{U^{Y}(i)}{C^{Y}(i)^{2}}
\end{aligned}
$$

The first partial derivative of labor:

$$
\begin{aligned}
U_{L(i)}^{Y} & =-\left\{C^{Y}(i)^{\sigma}(1-L(i))^{(1-\sigma)}\right\}^{-\gamma}(1-\sigma) C^{Y}(i)^{\sigma}(1-L(i))^{-\sigma} \\
& =-(1-\sigma) C^{Y}(i)^{\sigma-\gamma \sigma}(1-L(i))^{-\sigma-\gamma(1-\sigma)} \\
& =-(1-\sigma)(1-\gamma) \frac{U^{Y}(i)}{1-L(i)}
\end{aligned}
$$

The second partial derivative of labor:

$$
\begin{aligned}
U_{L(i), L(i)}^{Y} & =-(1-\sigma)(\sigma+\gamma(1-\sigma)) C^{Y}(i)^{\sigma-\gamma \sigma}(1-L(i))^{-\sigma-\gamma(1-\sigma)-1} \\
& =-(1-\sigma)(\sigma+\gamma(1-\sigma))(1-\gamma) \frac{U^{Y}(i)}{(1-L(i))^{2}}
\end{aligned}
$$

Due to the non-separable utility functions, the cross partial derivatives are non-zero:

$$
\begin{aligned}
U_{L(i), C^{Y}(i)}^{Y} & =-\sigma(1-\sigma)(1-\gamma) C^{Y}(i)^{\sigma-1-\gamma \sigma}(1-L(i))^{(1-\sigma)(1-\gamma)-1} \\
& =-\sigma(1-\sigma)(1-\gamma)^{2} \frac{U^{Y}(i)}{C^{Y}(i)(1-L(i))}
\end{aligned}
$$

Based on the partial derivatives above we can express the following ratios that can be used later

$$
\begin{aligned}
\frac{U_{C^{Y}(i), C^{Y}(i)}^{Y} C^{Y}(i)}{U_{C^{Y}(i)}^{Y}} & =\sigma-1-\gamma \sigma=-(\sigma(\gamma-1)+1) \\
\frac{U_{L(i), L(i)}^{Y} L(i)}{U_{L(i)}^{Y}} & =(\sigma+\gamma(1-\sigma)) \frac{L(i)}{1-L(i)}
\end{aligned}
$$


We can rewrite the approximated individual utility function:

$$
\begin{aligned}
U_{t}^{Y}(i) & =U^{Y}(i)+U_{C^{Y}(i)}^{Y} C^{Y}(i)\left\{\frac{C_{t}^{Y}(i)-C^{Y}(i)}{C^{Y}(i)}+\frac{1}{2} \frac{U_{C^{Y}(i), C^{Y}(i)}^{Y} C^{Y}(i)}{U_{C^{Y}(i)}^{Y}}\left(\frac{C_{t}^{Y}(i)-C^{Y}(i)}{C^{Y}(i)}\right)^{2}\right\}+ \\
& +U_{L(i)}^{Y} L(i)\left\{\frac{L_{t}(i)-L(i)}{L(i)}+\frac{1}{2} \frac{U_{L(i), L(i)}^{Y} L(i)}{U_{L(i)}^{Y}}\left(\frac{L_{t}(i)-L(i)}{L(i)}\right)^{2}\right\} \\
& +U_{C^{Y}(i), L(i)}^{Y}\left(C_{t}^{Y}(i)-C^{Y}(i)\right)\left(L_{t}(i)-L(i)\right)
\end{aligned}
$$

Rearranging the equation above:

$$
\begin{aligned}
U_{t}^{Y}(i) & =U^{Y}(i)+U_{C^{Y}(i)}^{Y} C^{Y}(i)\left(\hat{C}_{t}^{Y}(i)-\frac{\sigma(\gamma-1)}{2} \hat{C}_{t}^{Y}(i)^{2}\right)+ \\
& +U_{L}^{Y}(i) L(i)\left(\hat{L}_{t}(i)+\frac{1}{2}\left(1+(\sigma+\gamma(1-\sigma)) \frac{L(i)}{1-L(i)}\right) \hat{L}_{t}(i)^{2}\right) \\
& +U_{C^{Y}(i), L(i)}^{Y} C^{Y}(i) L(i) \hat{C}_{t}^{Y}(i) \hat{L}_{t}(i)
\end{aligned}
$$

We can use the results for $U_{C^{Y}(i)}^{Y}, U_{L(i)}^{Y}$ and $U_{C^{Y}(i), L(i)}^{Y}$ to simplify it further:

$$
\begin{aligned}
U_{t}^{Y}(i) & =U^{Y}(i)+\sigma(1-\gamma) U^{Y}(i)\left(\hat{C}_{t}^{Y}(i)-\frac{\sigma(\gamma-1)}{2} \hat{C}_{t}^{Y}(i)^{2}\right)+ \\
& -(1-\sigma)(1-\gamma) U^{Y}(i) \frac{L(i)}{1-L(i)}\left(\hat{L}_{t}(i)+\frac{1}{2}\left(1+(\sigma+\gamma(1-\sigma)) \frac{L(i)}{1-L(i)}\right) \hat{L}_{t}(i)^{2}\right) \\
& -\sigma(1-\sigma)(1-\gamma)^{2} U^{Y}(i) \frac{L(i)}{1-L(i)} \hat{C}_{t}^{Y}(i) \hat{L}_{t}(i)
\end{aligned}
$$

The labor demand and wage and price dispersion:

$$
\begin{aligned}
\hat{L}_{t} & =\log \int_{0}^{1}\left(\frac{V_{t}(j)}{V_{t}}\right)^{-\varphi_{W}} d j+\log \int_{0}^{1}\left(\frac{P_{t}(j)}{P_{t}}\right)^{-\varphi} d j+\hat{Y}_{t}+\hat{m} c_{t}-\hat{v}_{t} \\
& =\frac{\varphi_{W}}{2} \operatorname{var}\left(V_{t}(j)\right)+\frac{\varphi_{P}}{2} \operatorname{var}\left(P_{t}(j)\right)+\hat{Y}_{t}+\hat{m} c_{t}-\hat{v}_{t}
\end{aligned}
$$

The variances can given from Woodford (2003)

$$
\begin{aligned}
\frac{\varphi_{P}}{2} \operatorname{var}\left(P_{t}(j)\right) & =\frac{\varphi_{P}}{2 \lambda_{P}}\left(\pi_{t}-\gamma_{P} \pi_{t-1}\right)^{2} \\
\frac{\varphi_{W}}{2} \operatorname{var}\left(V_{t}(j)\right) & =\frac{\varphi_{W}}{2 \lambda_{V}}\left(\pi_{t}^{V}-\gamma_{P} \pi_{t-1}^{V}\right)^{2}
\end{aligned}
$$


The central bank minimizes the volatility of the variables:

$$
\begin{aligned}
\tilde{U}_{t}^{Y}(i) & =-\sigma(1-\gamma) U^{Y}(i) \frac{\sigma(\gamma-1)}{2} \hat{C}_{t}^{Y}(i)^{2}+ \\
& -(1-\sigma)(1-\gamma) U^{Y}(i) \frac{L(i)}{1-L(i)}\left(\frac{\varphi_{P}}{2 \lambda_{P}}\left(\pi_{t}-\gamma_{P} \pi_{t-1}\right)^{2}+\frac{\varphi_{W}}{2 \lambda_{V}}\left(\pi_{t}^{V}-\gamma_{P} \pi_{t-1}^{V}\right)^{2}\right)+ \\
& -(1-\sigma)(1-\gamma) U^{Y}(i) \frac{L(i)}{1-L(i)} \frac{1}{2}\left(1+(\sigma+\gamma(1-\sigma)) \frac{L(i)}{1-L(i)}\right) \hat{L}_{t}(i)^{2} \\
& -\sigma(1-\sigma)(1-\gamma)^{2} U^{Y}(i) \frac{L(i)}{1-L(i)} \hat{C}_{t}^{Y}(i) \hat{L}_{t}(i)
\end{aligned}
$$

where the approximated level of individual consumption and individual labor can be given by:

$$
\begin{aligned}
C_{t}^{Y}(i) & \approx \frac{C_{t}^{Y}}{N_{t}^{Y}}=\frac{\tilde{C}_{t}^{Y}}{s_{t}^{Y}} \\
L_{t}(i) & \approx \frac{L_{t}}{N_{t}^{Y}}=\frac{\tilde{L}_{t}}{s_{t}^{Y}}
\end{aligned}
$$




\section{A.3 Appendix: Welfare Functions and Optimal Reactions}

Figure A1: Welfare functions with the baseline monetary policy rules by ad hoc welfare leos
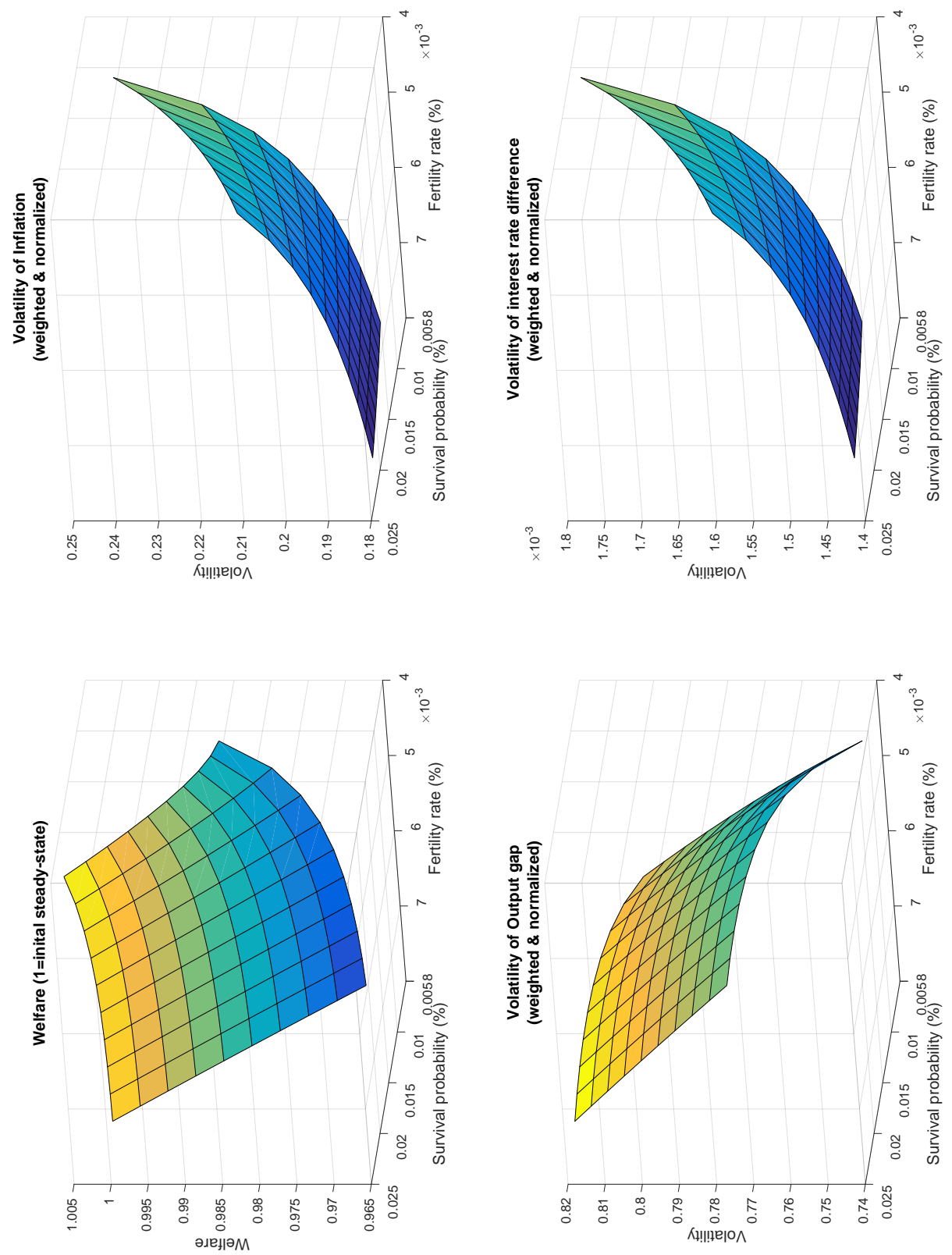
Figure A2: Optimal reactions by ad hoc welfare loss (1)
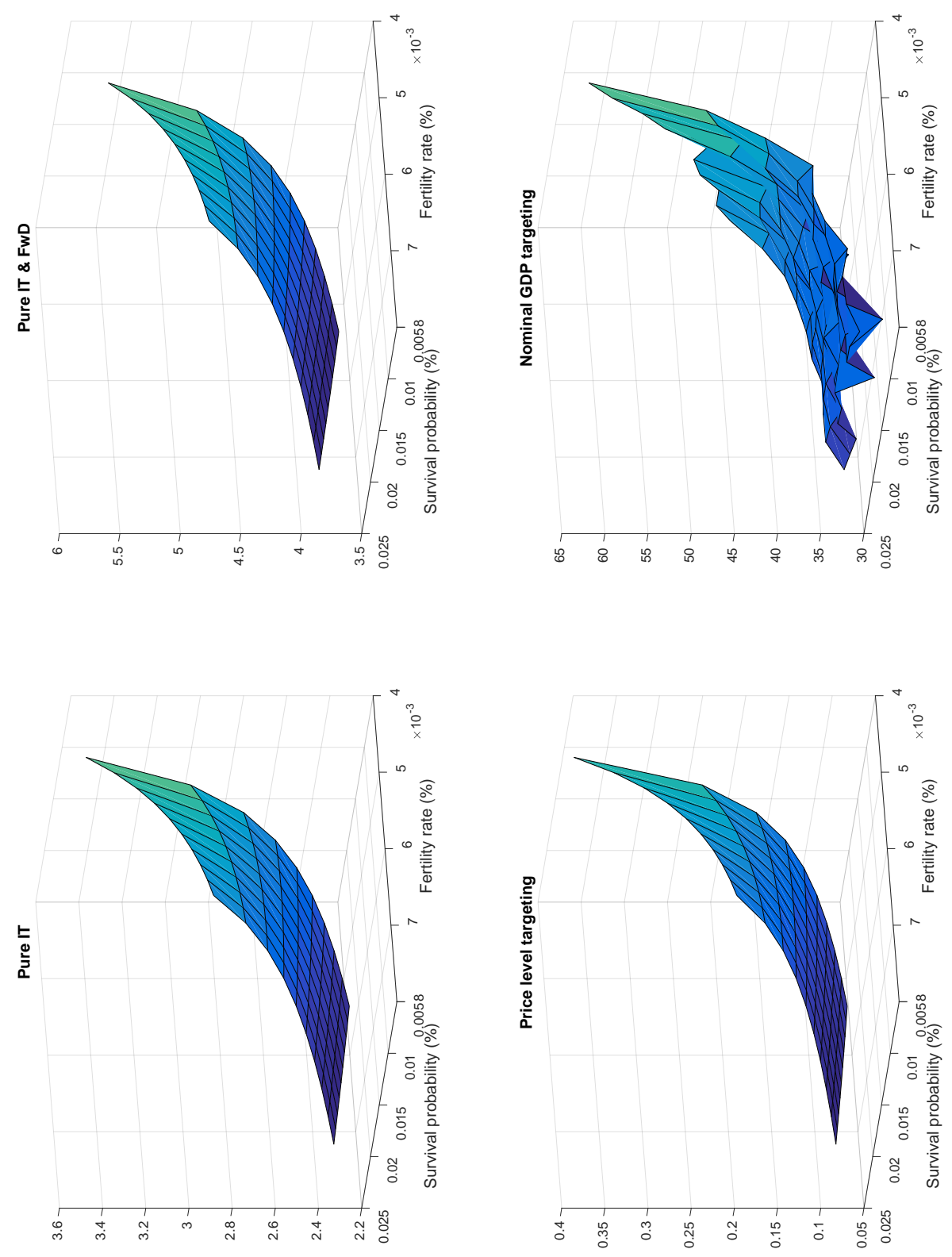
Figure A3: Optimal reactions by ad hoc welfare loss (2)
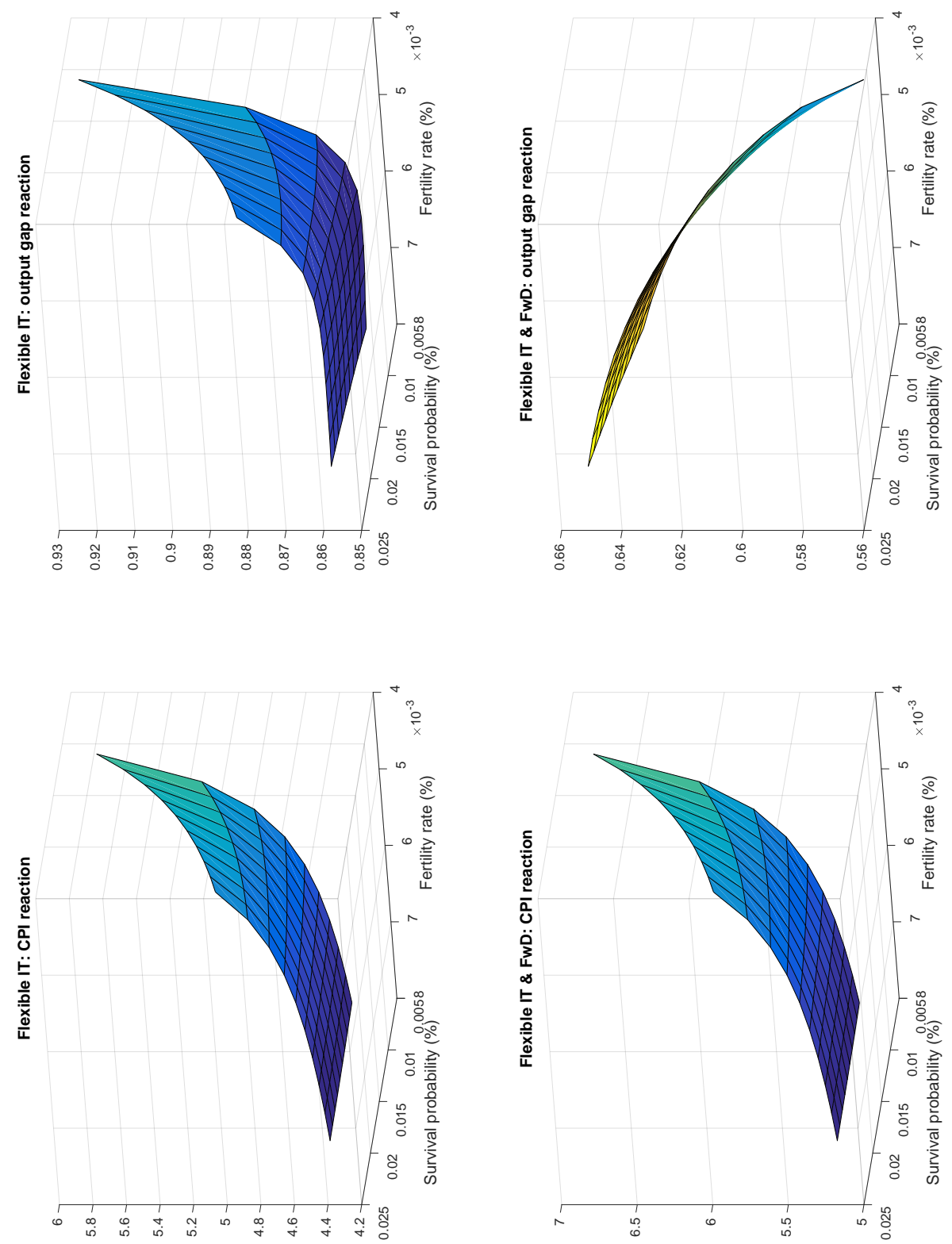
Figure A4: Welfare functions with the baseline monetary policy rules by utility function
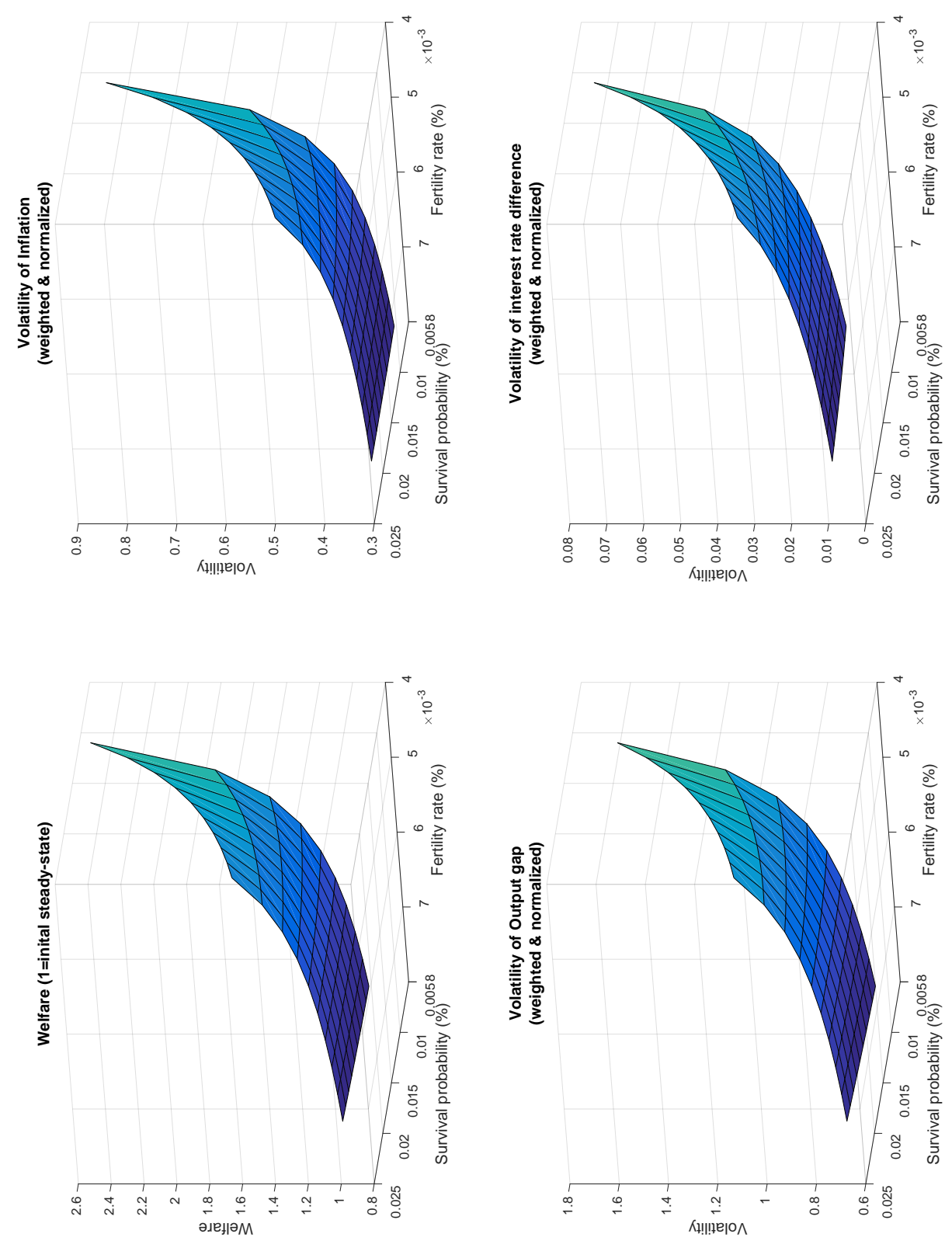
Figure A5: Optimal reactions by utility function (1)
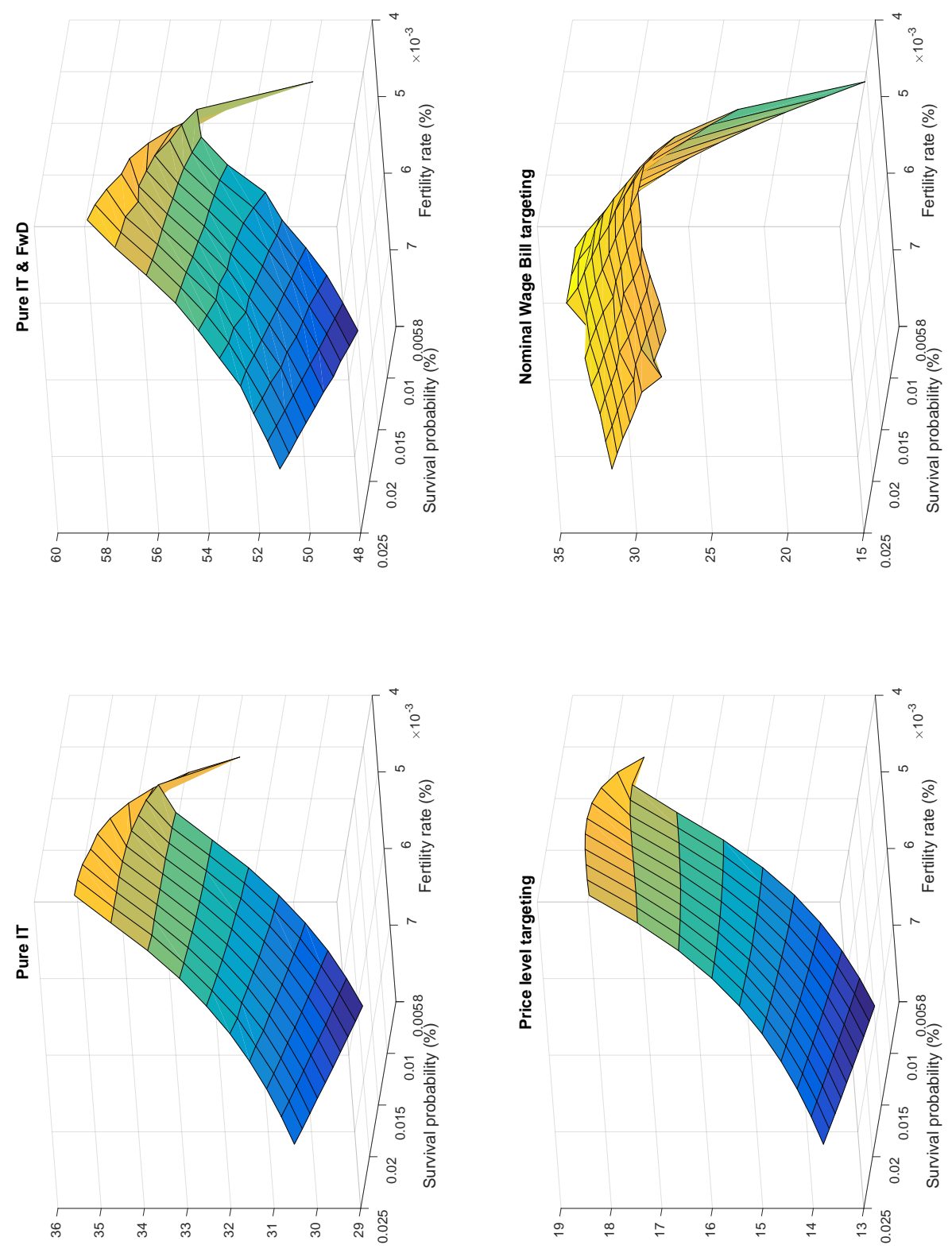
Figure A6: Optimal reactions by utility function (2)
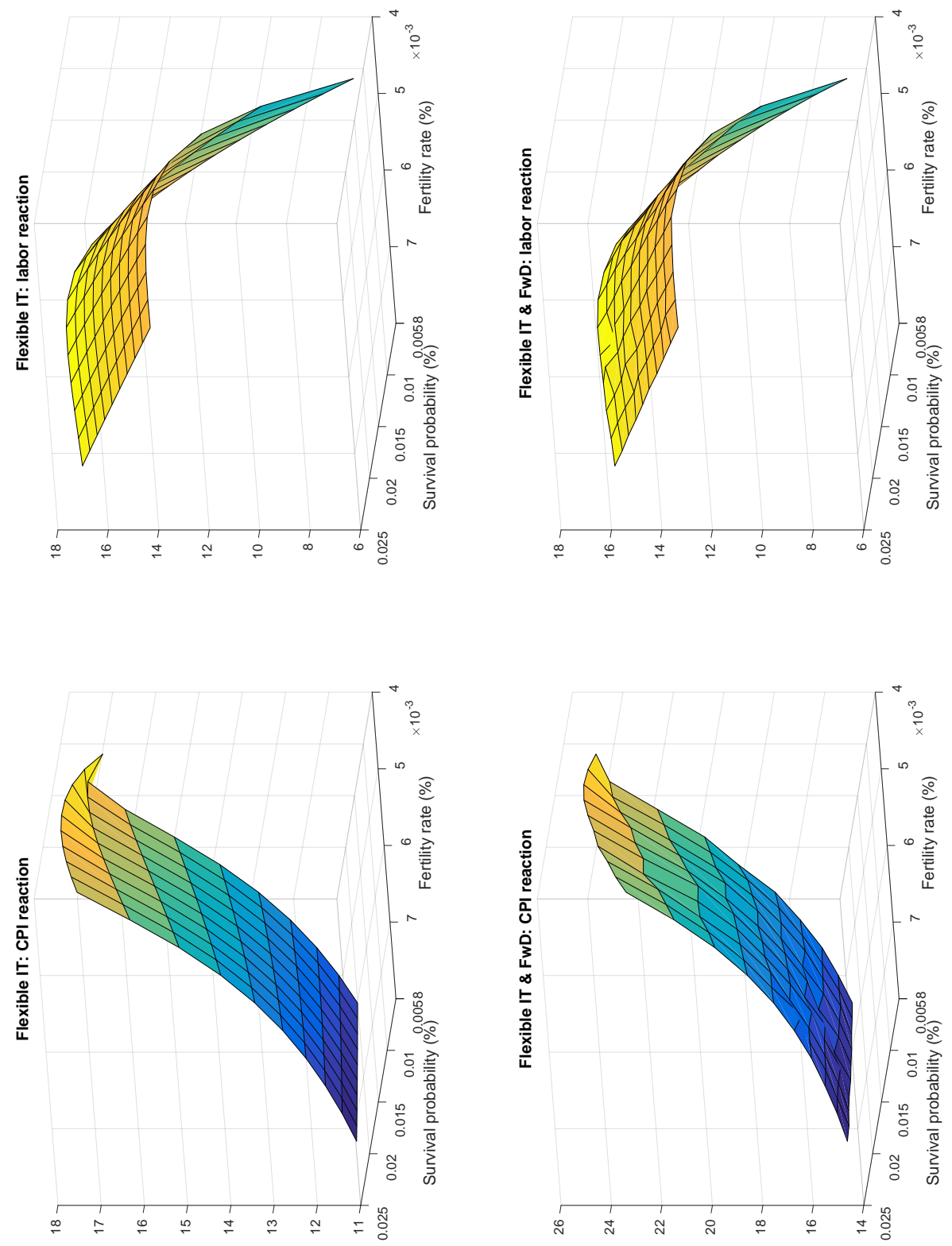